\title{
Rationalisation of Higher Education and the Postdigital Context
}

As anyone who has read The Labour of Words in Higher Education will be aware, I adopted the label of McPolicy to compare a rational method of writing HE policies (that has become widespread across universities) with humorous examples from consumer goods marketing:

I have noticed with interest though, that I can visit the supermarket and purchase a bottle of wine that has more 'body' attributed to it than a student or a lecturer within an HE policy. (Hayes, 2019: 7)

I argued too that:

Frivolous though that may sound, in a book that explores rationality and irrationality through nominalisation in university policy documents, cultural texts of different kinds are not separate from each other. What we read from a label on a commodity may have no obvious connection to a university strategy, yet both exist within a shared political economic culture. (Hayes, 2019: 7)

Building on Weber's theory of how bureaucracy once exemplified modern rationality, by coordinating the activities of large organisations towards a single objective, Ritzer has shown since that such rationalisation can spread from government and manufacturing processes into consumption and consumer services. My analysis of McPolicy was intended to show that such arguments might be extended even to written university strategy texts, that appear to also reflect the key principles of McDonaldisation that Ritzer discussed (Hayes, 2019).

As I introduce this chapter, I will pick up from where The Labour of Words in Higher Education left off in arguing that:

The concept of widening participation in HE has been adopted within narrow margins which can be broadened. (Hayes, 2019: 150) 
Strategic and practical work in relation to inclusivity, equality, diversity and participation in universities cannot sit apart from how digital technologies now relate to human life, risks, intelligence, opportunities and communications. Our shared political economy means there are points of interplay at every turn. Therefore, after initially setting up the context for this chapter, I will explain what the first and second halves of the chapter will address.

The language we use and the commercial platforms on which ideas are expressed are deeply intertwined with the data about each of us. As discussed earlier, we can think of language as intersecting across any number of situations (from communicable disease to communication over the Internet) where ideas spread due to 'contagious' aspects of language (Mann, 2018). Humans do though have the ability to query rational statements built on assumptions about the diverse positionalities and circumstances of others.

Questioning the reasoning behind any rationality and why a discourse is structured as it is, or how it could be otherwise, involves critically reflexive thought that draws on human experience. Humans imagine different futures and they express their ideas about these in natural language. This is a different form of processing of ideas to the quantification of human properties or attributes expressed as a number or written within a form of computer coding. Yet we have this shared problem too, that we have now literally 'become data'. As Cheney-Lippold (2018) points out, the data we have generated is the 'making of our digital selves' and it can be manipulated algorithmically to bring about futures where 'cloud ethics' (Amoore, 2020), rather than people, are deciding what it means to critically protest anything.

Even in recent novels, Sudjic (2021) points out that the 'personality' we think of as our own is being determined by algorithms and then harvested for data. As such, individuality is a 'stream-of-consciousness that is not entirely your own, that you participate in but also acts upon you' (Sudjic, 2021). Perhaps it is time then to bring this situation into critical dialogue with our 'postdigital selves' (Jandrić et al., 2018). To do so is to make connections with what it means to be postdigital, from our own positionality as a human with our own perceived identity. Such personal considerations need not be confined within anyone else's deterministic discourse about technology, or inclusivity. If our personal postdigital positionalities are shared, they can also support resistance to McPolicy and endeavours instead towards 'knowledge socialism' via 'collegiality, collaboration and collective intelligence' (Peters, Besley, Jandrić \& Zhu, 2020).

It can be helpful to recall that intelligence matters to each of us and that there are points of connection when we examine the roots of human and computer interactions and their links with philosophy (Russell \& Norvig, 2016). 
Universities exist around and for intelligence, but universities now also need to connect inclusivity strategies with stronger understandings of what it means for diversity and equality when we actually build intelligent entities (Russell \& Norvig, 2016). It is necessary to also consider what it means for inclusivity, diversity and equality when we build partnerships with the commercial providers whose platforms are now being 'powered' by new intelligent entities.

Our increasingly autonomous data-driven systems and all manner of new technologies come under the branch of computer science referred to as Artificial Intelligence (AI). Russell and Norvig (2016) discuss eight definitions of AI that they lay out across the four categories of thinking humanly and thinking rationally (concerned with thought processes and reasoning) and acting humanly and acting rationally (concerned with behaviour). Russell and Norvig (2016) suggest that thinking and acting humanly are concerned with success based on human performance. Whereas, thinking and acting rationally are concerned with measuring against an ideal performance measure, called: rationality. Whilst considering these categories, it is worth reflecting once more on the ideas from Steve Fuller, where 'human' is a normative category concerning what 'self-described' humans decide to include, or exclude (Fuller \& Jandrić, 2018). Fuller suggested reaching an agreement about the performance standards that a putative 'human' should meet that a 'non-human' does not. Then there were arguments that the identity of a human is constructed differently across the different disciplinary fields of computing and humanities (Poster, 1990) and suggestions that even as we explore the flow of digital humanities in our lives, we should not treat computing and humanities as 'equivalent' (Hall, 2013). We cannot afford to allow a one-way flow to impose a particular rational logic from computer science on the humanities: we need to bring new understandings of computing through humanities too (Hall, 2013: 782). This is a valuable 'postdigital dialogue' (Jandrić et al., 2018) that avoids the tired McPolicy rhetoric of a quick technological 'fix' and provides space to also examine the implications for equality, diversity and inclusion.

Often discussed as if this were a very recent phenomenon, the science of AI has been around for decades, with the term first attributed to John McCarthy in 1955 (Hyacinth, 2017: 15). To go back considerably further in terms of 'machine intelligence', Anthony Seldon (2020: 99) points to computational or counting devices such as 'the abacus in use in Babylonia as early as 2400 вС'. Tracing developments since, he discusses 'the earliest analogue computer designed to calculate astronomical positions', attributed to 'the Greeks in 100 BC' and adds that 'the slide rule was developed in the 1620's following the discovery of the concept of the algorithm [sic] by John Napier. In the early nineteenth century 'the first mechanical computer was devised by Charles Babbage' using punch 
cards and an integrated memory, with 'analogue computers using a mechanical or electrical model' following on in the 1920s, and digital computers by the late 1930s (Seldon, 2020:100). Perhaps we have been postdigital for longer than we realise.

Integral to this chapter though, is a recognition that underlying a rational discourse about any technology, or a rant on social media, are power relations linking wires, routers, data, software, systems, opportunities and inequities, with people, both online and offline. AI emphasises 'the creation of intelligent machines or programs that think, learn, and react like human beings' (Hyacinth, 2017: 15). It is the combination of hardware, software, data, methods, algorithms and technologies that make software 'smart' in a way 'that may seem human-like to an outside observer' (Hyacinth, 2017: 15). In more recent developments, wearable devices, household appliances and sensors connected to the Internet, that can be recognised by other devices to collect and process data, are referred to as the Internet of Things (IoT). When AI is added to the Internet of Things, these devices can analyse data, make decisions and act on that data without the involvement of humans, as the Artificial Intelligence of Things (AIoT) (Marr, 2019). Yet despite these apparently new developments, and a rational policy discourse that frequently places technology (rather than people) at the forefront of an ability to transform, James Ball reminds us that:

Systems don't build themselves. (Ball, 2020)

Discussing the promises of all that the Internet was once expected to bring for humanity, Ball explains how, rather than a democratising force, power has been concentrated and remains, in the places where it already existed. Discussing the hopes of the early 199os, the movement of the business world into the Internet, the WikiLeaks interventions to shift power and the Arab Spring protests against corrupt governments, Ball argues that our former mood of celebration of the Internet has been replaced with mistrust. Citing the appearance of World Wide Web creator Tim Berners Lee in 2012 at the London Olympics and his 'this is for everyone' tweet (Berners Lee, 2012), Ball flags up the contrast between the exultant dance festivities of nearly a decade ago, that revelled in shared ownership, and the current situation:

The Internet giants are viewed with mistrust, accused of playing a role in spreading misinformation, enforcing censorship and avoiding tax. Its billionaires are scrutinised and condemned for their working practices. Residences around the palaces of Silicon Valley have come to resent their corporate neighbours. (Ball, 202O) 
Ball makes some important distinctions though, between giants like Amazon, Facebook, Apple and Google, who are products of the Internet, and the structure of the Internet itself:

Despite its lofty language - the use of words like the 'cloud', language which suggests something free and natural, beyond the control of people - the internet is a network of physical cables and connections. It's a web of wires enmeshing the world, connecting huge data centres to one another and to us, storing and sharing the innermost details of our lives. (Ball, 2020)

Fictional though they may be, movies like The Net, the Terminator series, Enemy of the State and recent James Bond films (that I have found myself re-watching with family sometimes during lockdown) have depicted such networks and power grabs. It seems that even in the movies we can get a better sense of the cultural implications of technological developments than we can in education and the policy we write for it. These tales (even if they date quickly) are often unsettlingly close to technological developments we subsequently see emerging before our eyes. Then there are groups that have formed to examine the sorts of existential risks we see portrayed in the movies. Amongst the experts and donators on the scientific board, are also celebrities who have featured in such movies, supporting a key aim:

We humans should not ask what will happen in the future as if we were passive bystanders, when we in fact have the power to shape our own destiny. (Future of Life Institute, 2020)

The Future of Life Institute advocates education, research and intervention. It is necessary too to recall that our political economy is more advantageous for some people rather than others. We may all contribute to the enormous data pile, but people are positioned very differently in relation to it. As Ball points out:

Each of those cables is owned by someone, as is each of those data centres - and every piece of that data is also owned by someone, and that someone is almost never the person who that data is about. (Ball, 2020)

To lift our heads further out of the 'cloud', so to speak, Ball adds that each data owner:

Was backed and financed by someone, and each physical site lies in the jurisdiction of a government and a myriad of regulators. We refer to the 
online world as if it's abstract from the reality we all occupy every day: this is a myth, and it's a myth that obscures where the real power lies. (Ball, 2020)

Important for postdigital connections to be made concerning how each of us sees ourselves as positioned in this landscape, is the argument too that:

Online power is offline power: the internet has handed more power, control and money to the people who already had plenty. (Ball, 2020)

Digital change and the networked society have not fundamentally altered societal inequities then. Looking at this issue through a postdigital lens helps to avoid digital determinism and a churning out of related, rational and objective McPolicy. Examining individual postdigital positionalities reveals the unique subjectivities that will otherwise remain hidden. Placing these observations into the broad inclusivity agendas that universities seek to address, requires a very thorough and honest housekeeping exercise. Not only is it necessary to notice, include and critically discuss in inclusivity policy frameworks, the role of the Internet and the networked, data-driven commercial platforms used by universities, the places where these systems are reinforcing existing inequalities needs acknowledgement too.

Recognising the commercial purposes for which Virtual Learning Environments (VLES) and Learning Management Systems (LMS), as well as data analytics software were designed are a part of this, but there are now many more 'profit-oriented private organisations in education across the globe' (Verger, Lubienski \& Steiner-Khamsi, 2016). The Global Education Industry (GEI) consists of a huge number of money-making services and actors who provide datadriven systems, curriculum packages, private tutoring, certification, teacher training, recruitment of students, student services and accommodation (Verger, Lubienski \& Steiner-Khamsi, 2016). Powerful commercial coalitions (that have rapidly formed during the pandemic) now push for long term changes to education systems with serious risks for democratic public education to become irreversibly undermined (Selwyn, Macgilchrist \& Williamson, 2020: 25).

The first half of this chapter therefore explores this shared political economic culture in relation to how digital technology has become articulated in a narrow way in $\mathrm{HE}$ policy, and as a separate agenda from policies for inclusive practices. It examines the changes that universities have experienced and the challenges to their status as autonomous sites of knowledge. This leads into how the principles of McDonaldisation, that George Ritzer referred to as globally dominating (Ritzer, 1993, 2018) have developed in HE institutions (Hayes, D. \& Wynyard, 2002, Hayes, D., 2017). As universities have responded to the 
wider consumer culture of physical shopping malls and theme parks, McUniversities have followed suit (Ritzer, 2005, Hayes, D., 2017). There are many visible icons that demonstrate these patterns, but what is less visible are the commercial alliances behind the scenes of the McUniversity and the connections of these with the discourse of McPolicy (Hayes, 2019a). The McPolicy style of writing has framed a certain understanding of technology, by constructing it as a static, neutral set of tools to simply 'embed' in education and to automatically 'enhance' learning. For decades now, this rational assumption about digital platforms as something that educators can control has marginalised human positionality and people's individual, dialectical relations with technology in education. Strategies for Technology Enhanced Learning (TEL) have positioned academics and students in ways that have simply ignored diversity, with the intersection of these university strategy documents with inequality at an institutional level receiving little attention (Czerniewicz \& Rother, 2018, Hayes, 2019: 135).

However, to simply bring all university strategies under one framework for equality, diversity and inclusion does not cure the problem. In postdigital society, like the analogy of the airing cupboard, not all inequities are visible or easily accessible to respond to with a quick fix. Therefore, inclusivity policies cannot begin from a shared understanding that the principles of inclusive practice are well established' (Department for Education, 2017). Where do these principles begin or end in universities? Do they sit within or outside of the disciplines that we teach and the buildings that we occupy? Do we seek, as senior managers, to address via the words of institutional policy, every aspect of global citizenship experienced and contributed to by our students and staff? If so, then generalisations will not do. Recent events during the pandemic have disrupted any illusion that inclusive practices are either established or fixed.

Rather than seek to maintain a form of 'analogue McPolicy' where each new challenge must be embedded in the site of the HE institution, we can instead begin a more productive debate concerning 'postdigital policy'. This needs to first be contextualised in a long history of how computing technology has been positioned in society in support of capitalist inequities and discrimination. Ball observes:

The internet and the way it works were all human decisions, made by groups of men - its almost always men - in small rooms with their own particular ideologies, motivations and divisions. (Ball, 2020)

Ball calls the system behind the Internet 'overwhelmingly Western and overwhelmingly male' (Ball, 2020). It has been staring us in the face really, but the virtual airing cupboard has been so overflowing with our advertising, consumer 
temptations and cancel culture that (like the physical airing cupboard) we fail to see the underlying plumbing. However, if we really wish to address inclusive practices in our universities then we can no longer fail to engage with the inequities of what now powers all of our activities during a pandemic that is going nowhere fast.

If the Internet (used by more than three billion people in some form every day) has been shaped by Western males with their positionalities, ideologies and profit-making agendas underpinning its operation, then we have a major issue and a serious dichotomy. We use the Internet as our shared virtual airing cupboard. It is over the Internet that our debates about inclusivity and diversity themselves are raging every second of the day. If the Internet itself is fundamentally biased, then this is also shaping, to some extent, the online technologies and activities of staff, students and policymakers seeking to further and address inclusivity in HE. Ritzer might refer to this as another potential irrationality our rational, consumer-based (and also computer-based) approaches, have fuelled. If so, it is a big one and we are all implicated.

The recent data breaches experienced by universities, including Northumbria in the UK, provide further evidence that whilst HE may have joined the investors in commercial technology consortiums, this may not be as an equal partnership. Due to the amounts of data they amass, universities as well as charities are particularly susceptible to cyberattacks (Afifi-Sabet, 2020). They get targeted by ransomeware, phishing emails and malicious links:

Universities typically have complex and porous digital systems so attackers can often find their way back in repeatedly to cause more harm. (Hellard, 2020)

This though, takes the form of harm to individual students and staff. It is a subjective matter and not an objective issue, when portals are closed and clearing systems halted. The future plans of students become halted too. To go on trying to rationally 'embed' everything but the kitchen sink into university policy, risks taking responsibility for many things like this that we cannot hope to control. Whilst precautions can be put in place for staff and students to comply with, this does not address the fundamental cause of security problems. Furthermore, making objective statements about deeply subjective matters in strategies means that staff and students remain disconnected from the very policies that concern their safety.

The Covid-19 pandemic has demonstrated globally just how interlinked different social, economic, political and cultural policies are. It has shown how rational approaches (such as the A Level algorithm in the UK) can lead to 
irrationalities, if human positionalities are not considered. Take for example, the Covid-19 testing arrangements, as these are developing in the UK at the time of writing. There is a large human demand for testing and many drive-in testing locations have been set up to accommodate this. However, demand is not smooth, and it comes in surges. As people sought a test online, they were directed to testing locations hundreds of miles away from where they live, because in the system their local centre was shown to be at full capacity. Even as some attempted the long journey it turned out to be a longer one in practice, because the distances 'appear to have been calculated as the crow flies, rather than being a true reflection of how long it would take to drive' (Schraer \& Triggle, 2020). Such issues arising from both human and technological factors are proving a disincentive to being tested, which may mean some local increases in cases of the virus end up being overlooked, leading to new outbreaks (Schraer \& Triggle, 2020). Examples like this demonstrate how, depending on a person's situation, disadvantage can be further increased both through the design of digital platforms and the way that this plays out with physical circumstances during crises.

Complex cross-cultural connections, and how these intersect with digital systems, need therefore to be recognised as interlinked in policymaking for inclusivity. Continuing with the Covid-19 testing examples, there are postdigital dimensions to other technological errors. This can be seen in a recent data error in the UK where 15,841 positive tests were left off the figures reported because a daily test report in a CSV file was loaded into Microsoft Excel but the bottom rows of the spreadsheet were cut off (Hern, 2020).

Microsoft's spreadsheet software is one of the world's most popular business tools, but it is regularly implicated in errors which can be costly, or even dangerous, because of the ease with which it can be used in situations it was not designed for. (Hern, 2020)

Excel spreadsheets are easy, standalone applications that can be used by anyone, but this has become a regular problem now because the data input into these is not traceable and can be overtyped. As old technology encounters new systems, with human interventions along the way, it is not difficult to see how data errors can impact on human situations to cost lives, or alter individual health or work situations through error, bias, or discrimination. Policy discourse for inclusivity needs to reflect this postdigital positionality of individuals too, in order to move beyond rational and objective digital panaceas.

The second half of this chapter examines why recognition of shared political economic spaces of technology and culture are important for the airing of 
varied debates on what inclusivity means wherever individuals are positioned in postdigital society. In $\mathrm{HE}$, many strategies continue to be produced in isolation from each other, addressing separate topics and omitting interactions where inclusivity and technology intersect:

A first step is to review any lack of inclusivity present in the language in which these are written. (Hayes, 2019: 135)

This requires debates like the decolonising curriculum arguments to include a more critical examination of how all HE policy is linguistically constructed, and who and what is inputting into the policy process. HE policy language about inclusivity cannot be quarantined in some policies and not be present in others. Nor is it a separate discourse from government, media, business, marketing, public or theoretical discourse circulating in the virtual airing cupboard, on this very broad topic. Digital online communications systems and commercial platforms have made it easy for any dialogue to pick up traces from different institutional or personal positions, with implications for how inclusive practices in $\mathrm{HE}$, and related policy, are now constructed and perceived. Inclusivity discourse and data are not controlled within walls and (not unlike a pandemic) this requires open discussion on how to adjust to this, make changes and develop more inclusive policy:

Not least because contradictory statements around social justice risk cancelling each other out, if widening participation and student retention are enacted by generic statements, projects and technology, rather than diverse staff and students themselves. (Hayes, 2019a: 150)

Widening participation policy discourse now needs to widen further still. It needs to include, describe and acknowledge the activities, design, purposes and origins of data-driven digital platforms as these closely interlink with human endeavours:

The concept of widening participation in HE has been adopted within narrow margins which can be broadened. (Hayes, 2019a: 150)

In order to do this, it is necessary to notice interconnections where, for example:

Barriers to inclusivity, participation and social mobility can occur through the language of policy, as well as through the practices of recruitment. (Hayes, 2019a: 150) 
Examples in Chapter 1 revealed the various stances made by companies and individuals on different topics. These exchanges have relevance too for university equality, diversity and inclusion policies that seek to respect the identities and cultures of learners from diverse backgrounds, minority and migrant communities. $\mathrm{HE}$ is now closely interconnected with commercial platforms, images, icons, devices and systems for teaching, research and marketing activities. To put it humorously, universities cannot have their cake (or ice cream, even) and eat it. These commercial connections and the wider activities of companies that universities are now partnered with, are no longer separate from the policy statements that HE institutions make. It cannot be rationally argued or inferred that these systems can be entirely administered by academic institutions, as if they alone were in control of this agenda. Each human interaction with a system and the data it collects, has unique implications for the positionality of the person concerned. Associations arising from this are not confined within systems as they flow between virtual and physical spaces. This new postdigital context means that sustained habits of writing $\mathrm{HE}$ policies require a re-think. Repetitive assumptions in policy of what technology will achieve (Hayes, 2019a: 3) must instead acknowledge that all postdigital encounters are different, reflecting the positionality of the individuals involved.

A complex combination of factors plays out differently for each of us. However, both humans and computers may become objectively categorised in policy discourse. Ritzer has described extensions of his original theory to reflect augmented situations where humans may metaphorically occupy varying 'cages' of consumption (Ritzer, Jandrić \& Hayes, 2018). In Chapter 3 I will examine the situation of students in lockdown in relation to this analysis. However, in the second half of this chapter, I will consider how Ritzer's augmented cages may help to illustrate diverse postdigital positionalities. Humans who are now routinely subject to rational forms of computer processing and objective evaluation through McDonaldisation are also finding new ways to perceive their subjectivity. As Ritzer might put it, they are manipulating the bars of the rubber cages that they find themselves in (Ritzer, Jandrić \& Hayes, 2018). Covid-19 is a biological actor that is contributing to altering existing political economic spaces of technology and culture. The postdigital nature of these dynamic experiences and their relevance for inclusivity are key debates in HE policy reform.

\subsection{Rational Presuppositions That Technology Will Always 'Enhance'}

The technologies discussed in the introduction above have developed over decades in a shared political economic culture of capitalist values which have also 
altered how universities operate and are now perceived. Universities, which had more traditionally held an autonomy over knowledge (Delanty, 2001) have been subject to new forms of accountability (Power, 1997) rationality (Ritzer, 1993) and regulation. This has in turn had an impact on the academic labour of staff and students as universities have become increasingly incorporated into global markets (Slaughter \& Leslie, 1997). The rationalities that I refer to in policy discourse, reinforce these changes and related values, to cast technology in a simple calculation: 'as a guarantee that the use of technology will enhance learning' for profit (Hayes \& Bartholomew, 2015: 114). This is quite a presupposition given that technology means different things to different people in different situations and cannot simply be assumed to have inherent positive qualities where learning is always enhanced (Hayes \& Jandrić, 2014: 198). This is important too for discussion on postdigital positionality and the twofold debate that this book is concerned with. A simple logic of digital enhancement for everyone is inadequate for inclusive policymaking, particularly when there are new consequences emerging from:

The intelligence exhibited by machines by which it mimics cognitive functions that humans use, while interacting with other humans'. (Hyacinth, 2017:15)

Whose cognitive functions does it mimic? Or whose body image are systems of identification based on? Bias that has crept into the programming of technological systems has impact on how students are able to access education. Passports are used to verify student and staff identity in university application processes, but recently the UK Passport application process itself was shown to demonstrate bias. The 'website uses an automated check to detect poor quality photos which do not meet Home Office rules. These include having a neutral expression, a closed mouth and looking straight at the camera' (Ahmed, 2020).

Women with darker skin are more than twice as likely to be told their photos fail UK passport rules when they submit them online than lighterskinned men. (Ahmed, 2020)

Recently a black student challenged this algorithmic process that is used by millions of people as 'she was wrongly told her mouth looked open each time she uploaded five different photos to the government website' (Ahmed, 2020). The issues had arisen within the software, rather than the student's photo and she managed to get the photo approved eventually by writing a note to say her 
mouth was closed. This doesn't though solve the issue that such systems need to work well for everyone, regardless of facial differences and that:

The impact of automated systems on ethnic minority communities is regularly overlooked, with detrimental consequences. (Ahmed, 2020)

Furthermore, given that a freedom of information request in 2019 had already revealed that the Home Office were aware of the problem but had decided that the 'overall performance' was good enough to launch the online checker (Ahmed, 2020), this illustrates how systemic inequalities can play out across both computer and human bias. In another recent example, the already problematic UK contact-tracing app that had been sending out error messages encountered a 'fat finger error' (Corona24 News, 2020). Whilst this was quickly corrected it added to a number of reputational problems after 16 million people had already downloaded the app Such interactions, back and forth across human bodies and machines in individual contexts, are increasingly significant to any discussion about inclusivity in postdigital HE. In the passport example, facial detection accuracy was dependent on the diversity of the data the system had been fed into the training programme that was intended to 'teach' the computer what to search for. Linked discrimination occurs at human decisionmaking levels:

Discrimination can also be built into the way we categorise data and measure the performance of these technologies. The labels we use to classify racial, ethnic and gender groups reflect cultural norms, and could lead to racism and prejudice being built into automated systems. (Leslie, 2020)

Multiple and diverse 'actors' (that are not all human, and not all machine) are now altering much of what is still being described as 'established' or 'inclusive' practices in universities. Furthermore, these interactions have implications for human rights and equality (Equality and Human Rights Commission, 2017, Hector, 2020) and also for human capabilities (Sen, 1992: 87) as these intersect now with the powerful capabilities of digital platforms and data. Postdigital debate focuses a broader recognition of these relations, communications and exchanges that are now constantly passed between humans and intelligent machines, within a shared political economic culture. Positionality places the individual and their experiences as central. Perceptions of fairness are socially, culturally and technologically intertwined and intersect too with each person's identity and perceived capabilities. It is necessary then, to explore what this 
means across all of the key activities of $\mathrm{HE}$ (in relation to societal changes), to notice how educational access, inclusivity and opportunities for individual people are now altered in new, complex ways, depending on their positionality, in this dynamic context.

\subsection{Rationalisation of $\mathrm{HE}$ in a Neoliberal Political Economy}

Delanty (2001) has pointed out that: 'the history of western social and political systems of thought can be said to be the expression of a deeply rooted conflict between two kinds of knowledge: knowledge as science and knowledge as culture'. Writing two decades ago now, he argued that it is communication that is now transforming both knowledge and democracy. Through the age of modernity, 'from the Enlightenment to the postwar period, the institution of knowledge existed in a space outside the flow of communication. This place has been occupied mostly by the university. Knowledge has been seen as a site, a place that can be occupied by something called a university' (Delanty, 2001).

Delanty's insights on challenges to knowledge across recent decades are helpful in contextualising the twofold postdigital positionality debate. This is firstly, because the traditional role of a university as a knowledge provider is influential in circulating statements on the 'established' nature of inclusive practices. Assumptions like this come from a long tradition of being a site, or place, of knowledge. Decades of work in the areas of widening participation, lifelong learning and inclusivity for different groups across society have concerned the 'admittance' of individuals to this 'site'. It is a site that in many universities worldwide contains grand halls and theatres, like the large teaching room shown in Figure 23, where significant lectures, examinations, conferences and graduation ceremonies take place. Knowledge is imparted, assessed and celebrated, usually.

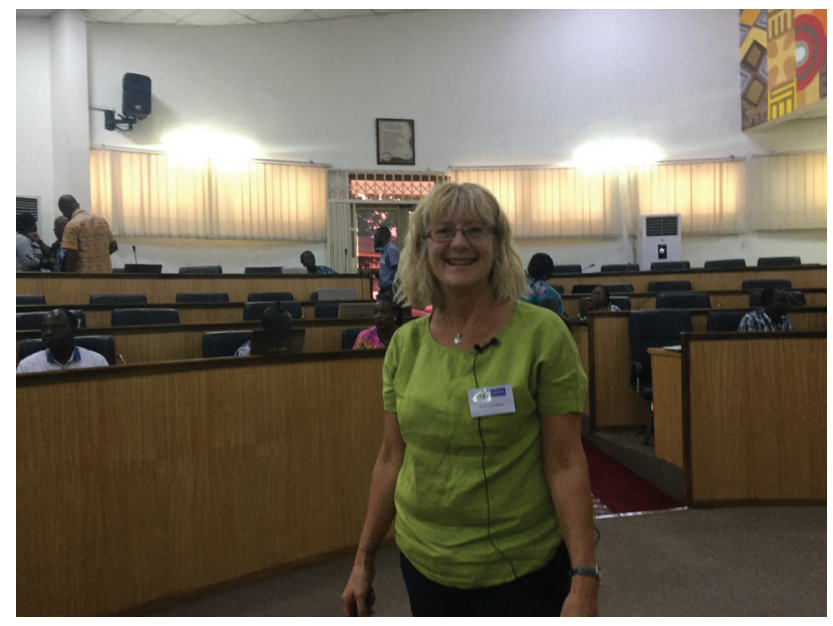

FIGURE 23

A lecture theatre where I taught in Ghana in 2019 
Covid-19, however, swiftly removed us all from these university sites across the globe, where alongside the rooms built for consumption of learning, are buildings that have emerged intended for consumption of entertainment, food and consumer goods, counselling, sport, cultural and social activities, as Ritzer might say, an array of 'cathedrals of consumption' (Ritzer, 2005). For many months these architectures were silent in the main, except for the laboratories loaned for the manufacture of sanitisers and ventilation equipment to fight the virus. In the wake of such a scale of disruption, it is worth paying attention to what this means for all of our futures in $\mathrm{HE}$ in a postdigital context.

Secondly, all of our key activities that have traditionally taken place in relation to this 'site' of the university might be better conceived now through implications for our personal and collective positionalities. Positionality is enacted wherever our location. It does not depend on admittance to a physical or virtual site, but it does articulate with our individual notions of inclusion in any of these spaces. Educational access, inclusivity and opportunities for individual people are altered in new ways though, now that we are conducting so many of these in a virtual airing cupboard. The discourse of McPolicy is a rational response from the site of institutions. Strategic plans have traditionally been written from within the university buildings, even if they are then placed on web pages and sent via emails. Yet attempting to maintain managerial or entrepreneurial control over technologies, communications and a worldwide network cannot be contained in this manner. Many authors have discussed the implications of neoliberal policy as it has become enacted within universities as measured outputs, strategic planning, performance indicators, quality assurance measures and academic audits (Slaughter \& Leslie, 1997; Shore \& Wright, 1999; Ball, 2003; Olssen \& Peters, 2005). 'University strategy discourse has provided a window on the rational arguments that support these measures. It is also a means to notice when these move towards irrationality' (Hayes, 2019a: 64).

Davies (2016) describes different phases and policy dynamics of neoliberalism over recent decades that have sought to 'prop up' a broken model of capitalist accumulation (Davies, 2016: 133). He argues that global capitalist development has become confounded by its own success, yielding irrational symptoms in an effort to preserve the status quo. He cites the recent reliance on digital technologies to yield solutions:

Increasingly, it is non-representational codes - of software, finance, human biology - that mediate between past, present and future, allowing society to cohere. Where, for example, employee engagement cannot be achieved via cultural or psychological means, increasingly business is looking to solutions such as wearable technology, that treat the worker 
as an item of fixed capital to be monitored physically, rather than human capital to be employed. (Davies, 2016: 133)

What remains as a problem is that such rational approaches omit the distinctive and varied aspects of whom we are, as individual people. They omit the communicative powers concerning knowledge that are now afforded to the wider population. Thus, they omit our global citizenship.

\subsection{Global Citizens and Semiotic Representations That Cross Academic Disciplines}

Where once the knowledge within a discipline appeared to be set within recognisable boundaries to communicate to students and to test their knowledge, now there are complex global entities that do not slot in so tidily into a room or lecture theatre where I might learn about science or history alone. Considerations of:

social justice, human rights, conflict resolution, environmental sustainability and diversity do not fall neatly into disciplines. (Ellis, 2019:1)

Ellis (2019) points out an interconnectivity between 'the human life-world and its experiential strata and domains', as such:

meaning falls into a stable typology, including performative, epistemic, and affective modes, and both sign types and types of language use anchor these modes as semantic formats in the discourses shared by human beings. Discourse structures, including the narrative, the argumentative, and the descriptive formats, ground the possible forms of knowledge available to a global citizen. (Ellis, 2019: 19)

Such complexities can be noticed when arguments arising from one disciplinary field can be noticed to omit valuable insights from another. However, across our disciplines:

Ethics, aesthetics, and critical thinking must now converge, in view of the contemporary threats. (Ellis, 2019:19)

Despite what it may say in the policies that I have analysed, technology cannot simply be used to address key challenges in $\mathrm{HE}$ or in wider society. $\mathrm{HE}$ no longer has the autonomy to meet these alone and there are threats that cut across all of our disciplinary areas. Recall, for example, the problems surrounding Covid-19 
testing in the opening to this chapter. Some universities have their own testing programmes, but still these are connected to the national records and open to the issues already discussed. To put it bluntly then, even in these days of selfdriving vehicles, no technology that I plug in will have a dialogue with me on how to address these dilemmas, or on what policy I should write. Instead, technologies are adding to the complexities that universities are encountering, as well as enabling new approaches to help us with tackling these collaboratively.

\subsection{McDonaldisation of HE and how McPolicy Frames Technology}

How people have become positioned in relation to digital technologies within rational policy texts about what these will 'enhance' for humans, has hampered more critical and inclusive dialogues (Hayes \& Jandrić, 2014, Hayes \& Jandrić, 2017, Hayes, 2019c). In $\mathrm{HE}$, this policy discourse has repeatedly reinforced the idea that: 'in exchange for the use of technology there will be enhanced forms of learning' (Hayes \& Bartholomew, 2015, Hayes, 2019a: 94). For decades, this dominant approach has inhibited 'questions being raised about the diverse ways students and their instructors really experience technology' (Hayes, 2019a: 94). It is these distinctive and varied aspects of who we are as people, and how we are individually placed, that are often omitted from all manner of McDonaldised rationalities (Ritzer, 1993, 2018). In recent years, for example, statements like this from educational institutions and government bodies have become commonplace. They illustrate how technology has also been closely linked to human achievement:

Technology can close achievement gaps, improve learning. (Stanford Graduate School of Education, 2014)

This reinforces a positioning of technology where it has been established as a common good in the links between social justice and education. The principle that technology 'improves learning' becomes the starting point for any discussions. This is rather like stating that 'the principles of inclusive practice are well established' (Department for Education, 2017). Any revisions to such principles are then not up for debate. However, the postdigital positioning of each one of us means that we now need to reopen both the debate on technology and the debate on inclusivity. This should not consist of separate HE policy discussions, as these are inextricably linked and intertwined with human experiences in the processes of accessing and participating in education.

Since universities have been held accountable for how students enter and progress through education, for the diversity of their intake and for how they demonstrate inclusivity, the role that digital technologies play in all of these 
processes requires stronger acknowledgement. In reports that tackle inequities, if technology is mentioned at all, it remains at the level of tackling barriers to accessing it, rather than deeper explorations of human agency, legibility and negotiability in relation to data driven systems (Mortier, Haddadi, Henderson, McAuley, Crowcroft \& Crabtree, 2020).

The different technological platforms by which many of us (but not all) exist, calls into question old interpretations of positionality based only on social positioning as a human. Now that so much of our lives is processed through digital systems, there are countless ways that those without devices, wifi or related skills to work online can fall through the cracks. Where once people received letters to home addresses, so much of this paperwork is now conducted through online systems. Yet many agencies continue to insist on proof of address. In a sense society never embraced the digital age entirely. The Covid-19 pandemic has revealed big disparities (ввС, 2020e) Therefore, to talk of a postdigital context is really to acknowledge the existence of digital, alongside and intertwined with, everything else.

\subsection{Inclusivity Policy Can Acknowledge, But Cannot Contain, Our 'Franchised Identities'}

Digital technologies have now enabled new complex forms of appropriation of individual identity and by association, positionality. This is a complex and messy situation, as old forms of media have become intertwined with new media technologies, programmes, devices, algorithms, politics and economics. New powerful hybrid forms, that are constituted by people, politics, economics and combinations of images, video, written and spoken text and programming code are influencing who, or what, people believe themselves to be or who they might become, 24/7. The concepts of personal identity and our own individual sense of belonging to anything in life, are no longer 'owned' by individuals alone. In the postdigital world, identity is constantly created and co-created for us, intersecting with our perceptions of who we are, or how included any of us may feel.

Private features of our existence that once sat apart from public gaze are available for reshaping, giving or selling back to us, across multiple physical and digital routes. Recalling the analogy of the airing cupboard, and the old adage of 'dirty laundry', click bait has provided us with virtual dirty secrets that keep us turning over the 'virtual sheets'. Headlines draw the eye and content marketers are the winners as people continue to click through the pages (Elliss, 2014). Click bait style headlines are a marketing tool deployed by many companies, but the willingness of people to overshare on social media has literally changed people themselves into click bait. Acting as what Ritzer would refer to as 'pro(con)sumers' (Ritzer, Jandrić \& Hayes, 2018), people upload for free their 
photos, judgements and 'half-baked thoughts' that live on indefinitely as 'digital breadcrumbs of the lives we used to lead' (Charles, 2020). The addictive nature of producing and consuming the mass of content on social media has led us to 'franchise our identities across two to three social networking platforms at a time' (Charles, 2020). This leaves each of us vulnerable to surveillance and datamining, but also our 'involuntary behaviours are being manipulated by social networking apps and sold on to the highest bidder' (Charles, 2020). Ashley 'Dotty' Charles refers to social media as 'unquestionably an era-defining innovation', but argues that it is:

Changing the way we come together, I worry that it has also made it easier for us to fall apart. So be sure that when you're using social media, it isn't actually using you. (Charles, 2020)

This apparently shared ownership of each person's identity in a postdigital context means that any aspects of who they are remain open to populist interpretations and virtuous signalling as well as to celebration, abuse and discrimination. I may be a female student of mixed race, or a white male with a disability, a parent, a traveller, a migrant or a refugee. Whatever combination of features I personally identify myself with, there are journalists, politicians, companies, educational leaders, policy makers, marketing experts and others, who will state across multiple forms of written and spoken media, who I am, what I require, who I should aspire to, or what I should become. Fake news and post-truth have become partners with each of us too, whether we welcome them or not (MacKenzie \& Bhatt, 2020). It is therefore necessary to 'understand the workings of digital technologies and how they are used in deception' (MacKenzie, Rose \& Bhatt, 2020). We don't have to be present on any digital platform for other people or things to invent or decide who any of us are and what we need. In terms of a wider therapeutic culture (Apperley, 2014, Furedi, 2016, Ecclestone \& Hayes, 2019) we may also begin to believe it.

Therefore, the Internet, its structure and data centres, the companies and platforms that own that data and the governments seeking to manipulate it, need to be uppermost in each of our minds when we log in. The attributes and capabilities we may consider to be part of humans alone, are also mechanised and measured both online and offline. Data is taken from us and different data is presented back to us. This changes the cultural nature of our personal data and it rationally alters its original connection with our individual positionality. If I, as a human and an academic, were to breach data ethics in some manner I would be subject to related inquiries and penalties. We are all though, in a situation of ethical compromise now as 'digital selves' formed by data 
(Cheney-Lippold, 2018) that is manipulated algorithmically in the 'cloud ethics' (Amoore, 2020). In earlier discussions concerning human attributes that are subject to such re-working, I made the distinction between a subjective awareness of our own personal attributes and a more objective set of attributes that an algorithm might repurpose in some way. Amoore's concern was that such algorithms 'condense multiple potential futures to a single output' and that this anticipation of our future propensities threatens the chances we have to make alternative political futures possible (Amoore, 2020:1).

Examining this issue in the broader political economy where universities have become increasingly marketised is a useful way to draw online and offline parallels. These can help to inform postdigital dialogue that builds on ecological rather than isolated understandings. In McPolicy human possibilities are reduced through restrictive and controlling language that rationally presents one view on the world. As such, McPolicy, not unlike an algorithm, may also 'condense multiple potential futures to a single output'. By anticipating what students will encounter as 'the student experience' or presenting to students a set of objective attributes to attain, this controlling discourse cuts off possible alternative futures for both students and staff. As just one offline example, we can even find random attributes presented back to us in imagery around campus, making university premises (as well as online systems) indistinguishable from those of corporate business.

\subsection{The Visible Icons of Higher Education}

At the beginning of The Labour of Words in Higher Education, I commented that people appear to be facing multiple forms of displacement across society (whether via technological unemployment, automation or dehumanised statements in policy language). Yet human beings (it would seem) are still seeking to 'preserve something of themselves across both the digital and material worlds' (Hayes, 2019a). I pointed to different ways in which human attributes have been linguistically detached from their owners in many HE policy texts:

This vision of student success, in the form of employability, appears to involve breaking down what constitutes a student, in terms of sets of attributes and assets. The body is not just alienated, it is dismantled. McPolicy discourse thus sets up the conditions for multiple routes towards marginalisation and fragmentation of human labour. (Hayes, 2019a: 128)

Iconography plays its role alongside such discourse in HE. Visual banners have become commonplace on university campuses and have been reproduced across institutional web pages. 
During the pandemic lockdowns these will have gathered dust somewhat in the absence of many people to view them, but they are notable nonetheless for the way in which they reinforce generality, rather than individual, diverse forms of positionality.

One example is the way that, many universities have reproduced single words describing detached attributes or values on posters and banners.

Some of these are engraved these into windows of classrooms and study spaces (as in Figures 24, 25 and 26).

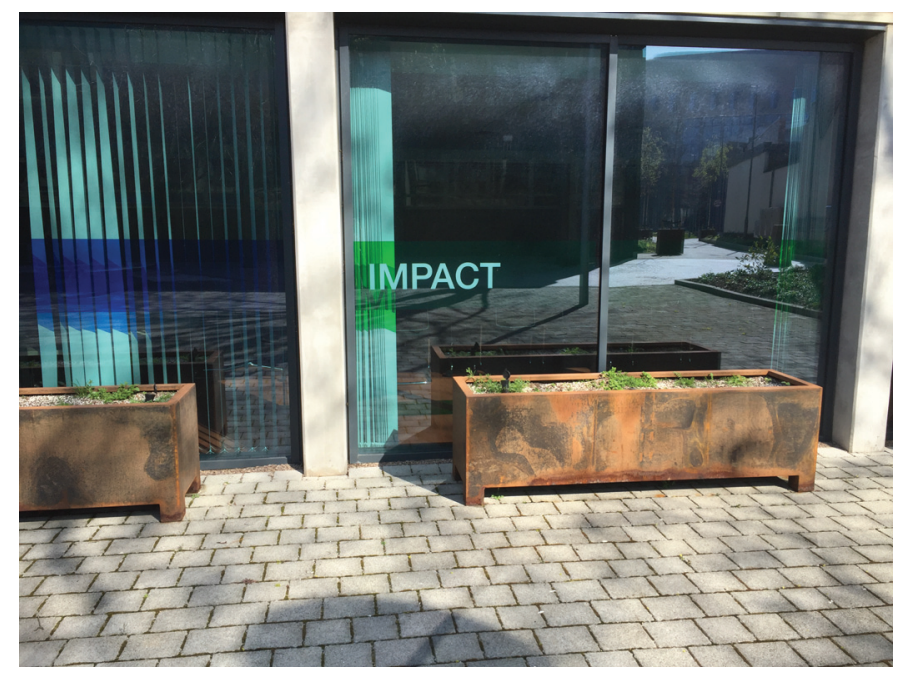

FIGURE 24 A university window displays the word 'IMPACT'

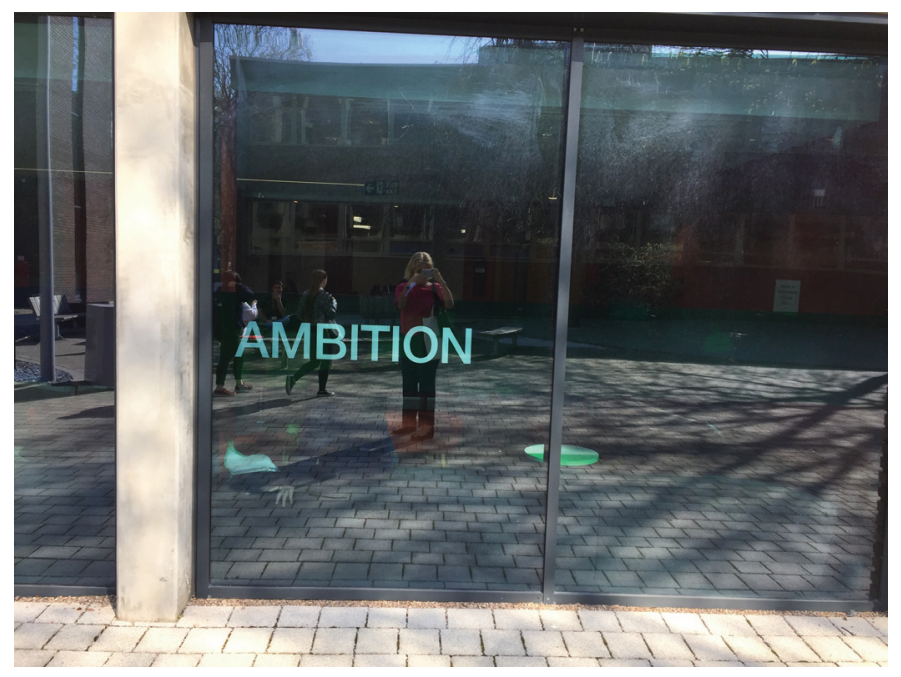

FIGURE 25 A university window displays the word 'AмBITION' 


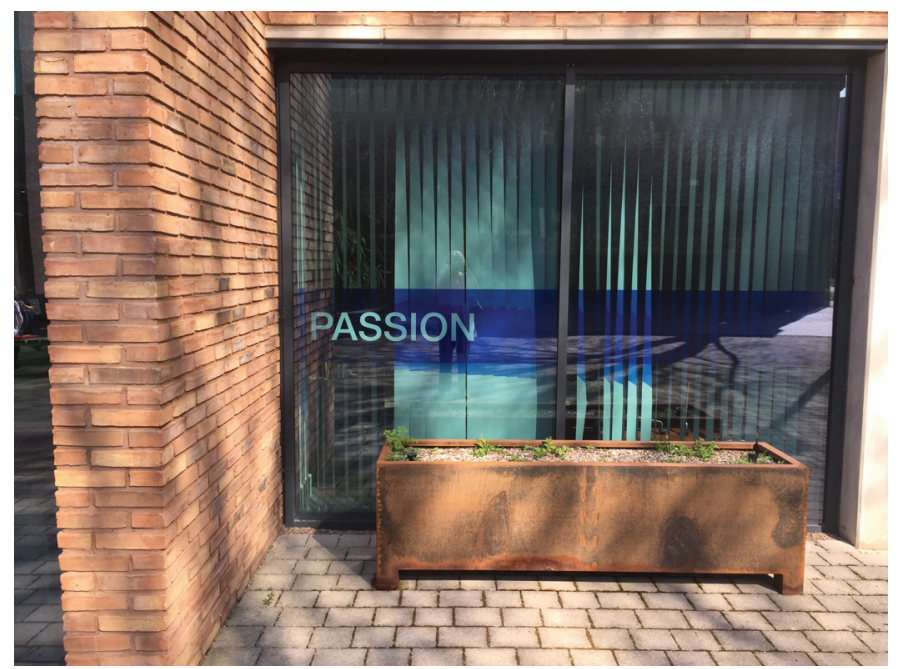

FIGURE 26 A university window displays the word 'PASSION'

This form of iconography appears innocent enough, but it is also part of our shared political economic culture of capitalist values. The same approach is to be found across many other businesses and sports grounds (Figures 27 and 28). In isolating these single attributes away from personal context this tends to 'cancel' more individual and creative interpretations of what these values actually mean to diverse members of the population.

Given that we live in a world of 'overwhelming pictorial content', Lacković (2O20a) argues that 'a turn to examining and understanding digital communication mediated by pictures can be beneficial for contemporary higher education (Lacković, 2020: 444). This has been argued to be overdue when some authors were pointing to a form of academic iconophobia (fear of images) in the early 1980s (Sless, 1981) and 'this situation still prevails' (Lacković, 2020: 444). Lacković and Olteanu (2O2Ob) argue that HE needs to respond to 'an unprecedented profusion of visual information across digital media' and to 'counteract the uncritical consumption of images from the perspective of semiotics' (Lacković \& Olteanu, 202ob).

Miltner and Highfield (2017) have discussed the popularity of the Graphics Interchange Format (GIF) across the Internet. They point out that while the GIF has certain technical affordances that make it highly versatile, this is not the sole reason for its ubiquity:

GIFs have become a key communication tool in contemporary digital cultures thanks to a combination of their features, constraints, and affordances. GIFs are polysemic, largely because they are isolated snippets of larger texts. This, combined with their endless, looping repetition, allows 


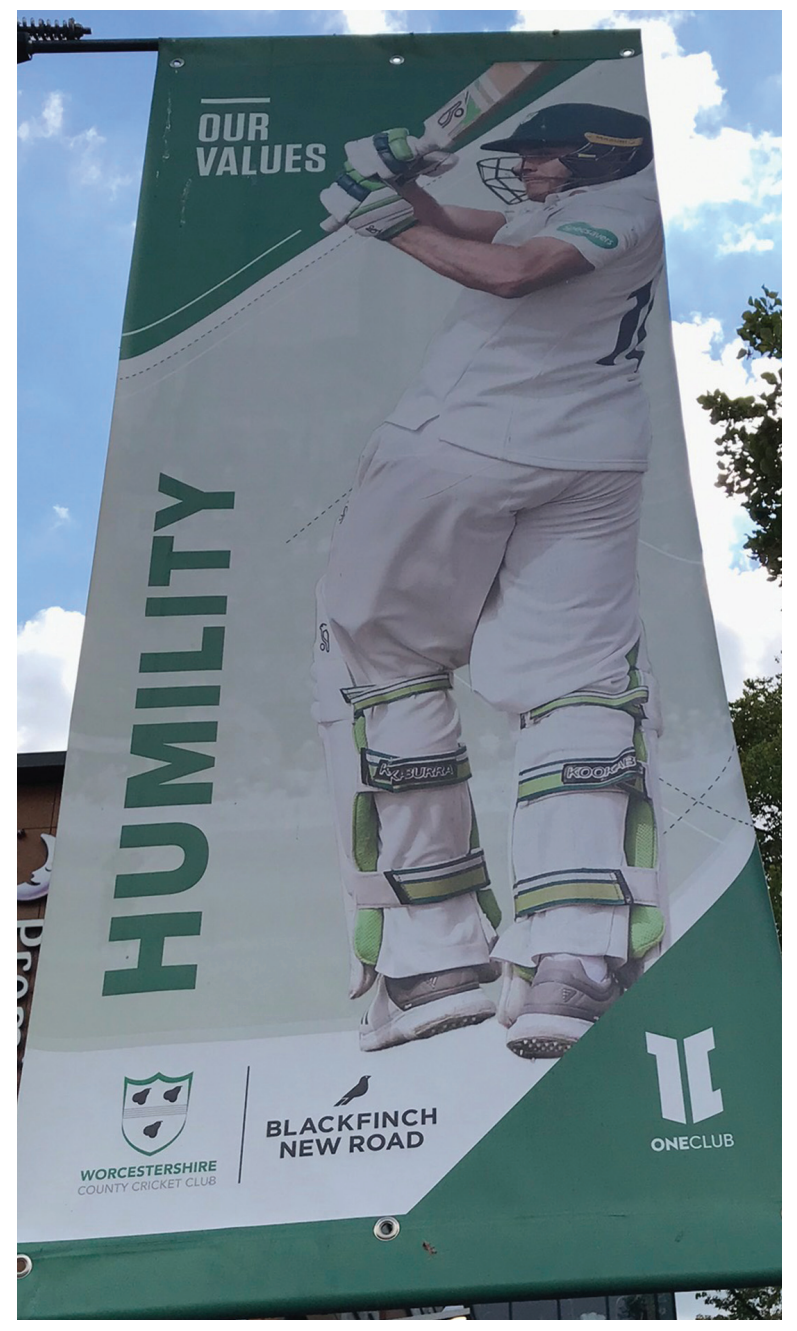

FIGURE 27

The word 'HUMILITY' is displayed on a banner outside a cricket ground

them to relay multiple levels of meaning in a single GIF. This symbolic complexity makes them an ideal tool for enhancing two core aspects of digital communication: the performance of affect and the demonstration of cultural knowledge. (Miltner \& Highfield, 2017:2-3)

People are able to use GIFs to open and close down debate over social media, as powerful communication tools that carry cultural meaning to huge numbers of followers. GIFs impart quick, powerful messages, are multi-generational and are not confined within linguistic boundaries. They can add humour, draw people in and can be inclusive in enabling anyone join an online conversation. On a less inclusive note, Lauren Michelle Jackson (2017) has pointed to a recurring problem of 'digital blackface' where: 


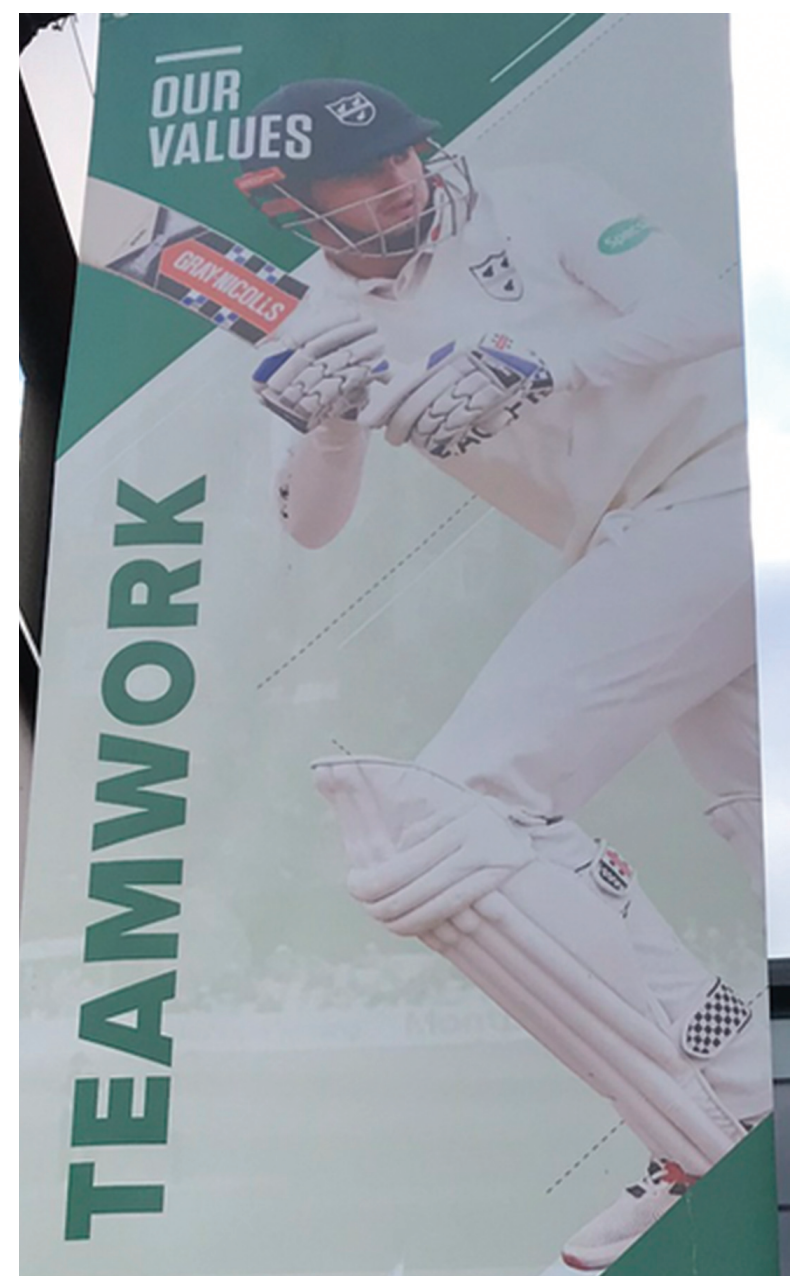

FIGURE 28

The word 'TEAMWORK' is displayed on a banner outside a cricket ground

the tenets of minstrel performance remain alive today in television, movies, music and, in its most advanced iteration, on the Internet. (Jackson, 2017)

Jackson raises this concern, citing many examples to show how non-black users tend to adopt GIFs with black people in them for emitting their most exaggerated emotions, arguing too that:

No digital behaviour exists in a deracialized vacuum. (Jackson, 2017)

Whilst those of us who have taught critical media and popular culture courses may discuss examples like this with our students, the implications of all kinds of digital discrimination need to be understood beyond the contexts of 
teaching and research alone, in universities. Multi-level forms of discrimination, via images and videos as well as texts, need to be acknowledged alongside the data-driven platforms they appear on within university policymaking that seeks to promote inclusive practices. This is necessary given the biased meanings that pictures, digital photographs and material icons can both embody and project.

\section{$1.7 \quad$ Less Visible Aspects of Commercial Alliances in $\mathrm{HE}$}

Universities are rapidly becoming 'powered by artificial intelligence' and performance metrics in an increasingly market-driven sector (Williamson, $2019 b)$. Such agendas now also share platforms with life-changing decisionmaking algorithms' that are 'infected with biases' (McDonald, 2019). These changes give rise to new ethical considerations of who, or what, can be trusted when academic life is increasingly structured via commercial as well as political interests. Universities are no longer simply commodifying and selling their own services commercially. Private companies have become an essential constitutive part of the $\mathrm{HE}$ industry, raising questions about the 'consequences for university teaching, research and societal roles more broadly' (Komljenovic, 2018). The reliance on commercial systems during the pandemic has brought this further to light, alongside challenges too that demonstrate that our systems 'are only as good as the humans producing them' (Seldon, 2020: 2).

Meanwhile, AI and AIoT are not obviously reminding us of their presence, but examples in the remainder of this chapter reveal why the postdigital nature of their activities cannot be excluded from HE debate on inclusivity, inequalities, diversity, discrimination and cancel culture. Digital technologies are intimately meeting with us at every intersection of human identity (Crenshaw, 1989, McCall, 2005). A sector-wide (and cross-sector) debate is needed to focus on how people are positioned as unique individuals amid this complex interplay of data, software and media communications described above. This concerns the roles that technological platforms and devices play (or don't play) in peoples' individual lives, their biological and physical circumstances and their social, political and economic contexts. The individual experiences and postdigital circumstances surrounding humans have implications across all of the key activities of HE. Educational access, inclusivity and opportunities for individuals can now be altered in many new ways, depending on their positionality.

\subsection{Intersectional Adhesives}

Intersectionality has brought valuable theoretical perspectives to bear on the intricacies of identity, diversity and inequalities, but McCall (2005) has argued 
that the older fields in the social sciences 'still have yet to deal fully with the complexity inherent in intersectional studies' McCall (2005: 1795). Disciplinary and interdisciplinary boundaries tend to conceal all kinds of connections that might be noticed between valuable research that explores intersectionality from different perspectives. With so many recent digital developments, intersectional computing (Kumar \& Karusala, 2019) is now using the concept of intersectionality to potentially act as a form of 'glue' to bring together disparate domains of computing, with the field of Human Computer Interaction (HCI) 'now finding its way into conversations around equity, diversity and social justice' (Kumar \& Karusala, 2019: 51). Whilst this is an unfolding discourse, its focus has become concentrated on:

populations marginalised in a few explicit ways, mainly around the constructs of race, gender and class. There are also less explicit marginalised aspects of identity that a deeper engagement with the lens of intersectionality might surface, such as nationality, domain of work and linguistic ability among others. (Kumar \& Karusala, 2019: 51)

Any number of aspects of each of our identities now also intersects with the postdigital contexts we find ourselves in. Subjective discussions on how we interpret these interactions offer a valuable form of resistance to rational statements that impose categories on individuals. Such classifications make their way into inclusivity policies through socially constructed labels that become applied to different sections of society. It is worth each of us questioning though, is the world really like this? How can space be opened in our university inclusivity policies for individual interpretations, and not blanket suppositions, to be heard?

In contrast to generic labels placed on humans are the fluid and personal ways in which each of us understands ourselves. Taking the experience of bell hooks as an example, she describes a subordination of her own positionality when others represent her:

Because so much of the work I have done within feminist theory and cultural studies interrogates the way images are constructed to perpetuate and maintain sexism and racism, I am utterly mindful of the way in which my own understanding of what it is to be a black woman insurgent/intellectual writer is increasingly subordinated to the way in which I am represented by various structures of that white supremacist capitalist patriarchy I have spent my adult life critiquing. (hooks, 1996: 814) 
Asking questions about how the Internet has since maintained or disrupted such deeply personal understandings of identity cannot simply be concentrated at the level of culture wars across social media. In terms of computing and the design and construction of the technical platforms that we use to air our views on, intersections also influence the lives of the:

Researchers designers and practitioners responsible for advancing the discipline overall, and the active and passive users whose lives are shaped by these advancements. (Kumar \& Karusala, 2019: $5^{2}$ )

Thus, wherever we find ourselves in the virtual airing cupboard, complex intersections underpin both the people and the platforms. James Ball (2020: 233) points out that where the Internet is concerned 'we moved fast and we broke things, and we didn't act quickly enough to repair the damage as we did so' (Ball, 2020: 233). This sounds like we now need to hire a very talented plumber to attend to the many elite interests that have dominated our shared virtual airing cupboard if we are to turn threats to opportunities. Ball suggests though that we:

Break it down into getting small things done, rather than trying to build the communications backbone of the world in one go. We know it can be done because it's been done before. It's the next step of the technological revolution, and it's in our hands. (Ball, 2020: 233)

Reflecting on such plans in postdigital terms is one way to disrupt a one size fits all approach to who, or what, gets included. It enables a refocusing of issues to include the past, present and future theories and technologies that remain in our social contexts. There is no reason why we can't bring some of our older technologies into the debate with the newer ones whilst we are seeking to reset education and inclusivity policies beyond Covid-19. So far, my airing cupboard has served only as an amusing analogy, but I am not yet ruling out its fuller participation in our plans for the future, when I hear of robots learning to knit.

\subsection{Exploring Shared Activities between Humans and Computing to Progress Inclusivity}

Treusch, Berger and Rosner (2020) take the 'messy and seemingly unproductive process' of teaching a commercial robot to knit as a way to examine technological limitations and tensions arising from a potential collaborative practice: 'the uselessness of the chosen task allows us to re-consider the idealization of 
robotic collaboration'. By 'drawing on performative explorations and critique, we show how knitting enlarges our capacity to visualize what might be a suitable use case for cobots' (Treusch, Berger \& Rosner, 2020). The notion of human collaboration with robots is particularly important given their potential for involvement in most spheres of human activity now. This is discussed in the context of 'cobots' 'as powerful contributors to a workforce and as powerful cultural figures':

Envisioned as a co-worker and not as a substitute worker, the cobot exposes the possibility of building new interfaces of proximity between humans and cobots. (Treusch, Berger \& Rosner, 2020)

Could this novel approach enlighten us on future postdigital dialogue (Jandrić et al., 2018) between humanities and computing to progress inclusivity, and to begin to close the gaps highlighted by Delanty (2001) and address challenges raised earlier by Mark Poster (1990) and Gary Hall (2013)?

Before I get too carried away though, moving from the example of knitting in $\mathrm{HCI}$ to another involving condoms, demonstrates multiple intersecting agendas that can also hamper shared goals. In their paper examining sexual health workers 'talk' around a condom distribution scheme, and implementation of a digital system to support this, 'problematic ideologies around young people and sexuality were exercised and reproduced' (Wood, Garbett, Morrissey, Hopkins \& Balaam, 2018). The authors of this study found that despite calls to develop more holistic models of sexual health in national guidelines and international sexual health strategies, when a digital system was introduced, dominant and controlling models of sexual health discourse and rational efficiencies to prevent disease prevailed over community development models.

The sociotechnical approach met with the socioeconomic setting of the sexual health service where the positionality of the young people was imposed upon them 'as potential deviants requiring management and control'. This omitted multiple cultural, legal, political and economic circumstances that studies have shown to influence sexual and reproductive health in young people. Not unlike educational settings, sexual health workers in the UK operate in a context of targets and responsibility for sexual health is positioned at the individual level rather than the collective. The digital service implemented served to prop up this agenda rather than to provide space for the diverse positionalities of the participants (Wood, Garbett, Morrissey, Hopkins \& Balaam, 2018). For these researchers conducting this digital study, a framing of the users as potential deviants meant that they were unable to retain the values of usercentred design, participation, and community approaches to sexual health in 
conducting applied, collaborative research. Thus, the role of digital technology was also problematised (Wood, Garbett, Morrissey, Hopkins \& Balaam, 2018: 10).

Ultimately then, if McDonaldised models of efficiency, calculability predictability and control prevail to reinforce top-down assumptions, then this tends to pose considerable challenges to user-centred participation and design. There are implications for inclusivity policies in universities that omit sociotechnical concerns from their detailed frameworks. One of the strengths of examining positionality through a postdigital lens is that it helps to reveal how (in very different social and technological situations) rational exclusive McDonaldised models might be noticed and disrupted to promote more diverse and inclusive ones.

Clarke and Schoonmaker (2020: 1) examined the problem of metadata in relation to publishing and asked: 'who has the power to decide what is accurate?' Whilst materials by people from diverse communities that reflect their identities, stories, and experiences are vital to social equity and empowerment of marginalised people, these are not prominent in the searches undertaken by traditionally mainstream communities. They are needed though, in order to see the world from alternative and empathetic perspectives. Library metadata is generally treated as factual and authoritative. This excludes, rather than includes, many marginalised communities. The researchers created a prototype to intentionally promote U.S. library resources by authors from traditionally marginalised communities, such as ethnic minorities, women, people of non-cisgenders, indigenous peoples, people identifying as LGBTQIA+, and people with disabilities (Clarke \& Schoonmaker, 2020: 1). Whilst their technical goal was to develop wider access, their process of creation drew on critical design principles intended to raise questions and debate, rather than a purely technical fix to address deeply social concerns. They employed 'tricksterism' in the design process which 'actively lays bare the problematic ethics of our metadata interventions' (Clarke \& Schoonmaker, 2020: 9). By intentionally transgressing boundaries in library metadata practices, they called into question the ethics of those practices themselves, such as what constitutes 'good' practice and when does it become 'bad', if it is redirected to advance social justice causes? Applying an amoral tricksterism to the design process enabled the designers to work in 'an ethical grey area and provoke questions about what a tool for justice might look like'. Through different use cases and bibliographic records, they demonstrated ways to open pathways for new design decisions that might potentially incorporate and reflect complex intersectional identities (Clarke \& Schoonmaker, 2020: 10).

The need for disruptive design is further upheld by Adamu (2020) who discusses what is missing from the Human-Computer Interaction for Development 
(HCI4D) literature in terms of 'the African standpoint logic'. Adamu (2020: 6 ) argues that positional understandings of African values are necessary for transcultural technological design:

Innovative practices can be envisioned when the complex and interweaving formation and orderliness of members' social life is placed centrally in technological discourse, which will help to understand, design, develop, evaluate and deploy technologies in an Africa context. (Adamu, 2020: 6)

Clarke and Schoonmaker (2020) and Adamu (2020) each highlight different but related postdigital challenges for representation and positionality. These can arise in the act of, for example, routinely retrieving literature from the same 'echo chambers which reflect the first five or ten pages of Google Scholar' (Jandrić, 2019) and thereby missing so many possible alternate sources, due to the way metadata has been set up. Or designing systems, or selecting these for use, in international development countries based on rational assumptions that omit cultural context (Traxler, Smith, Scott \& Hayes, 2020). It is necessary though to disrupt our humanities theories as well as our computer design assumptions. For example, members of groups such as the 'critical pedagogy movement tend to read (and cite) other members of the critical pedagogy movement' (Jandrić, 2019). This is an accepted academic practice across many disciplines and knowledge communities but can also become an exclusive one. A dual acknowledgement of a need to disrupt both humanities and computing practices could be a powerful route forward, as these go hand-in-hand in our postdigital knowledge production:

The process of publishing is a form of 'social production' that takes place across the economy, politics and culture, all of which are in turn accommodating both old and new technology in our postdigital age. Technologies such as software cannot be separated from human labour, academic centres cannot be looked at in isolation from their margins, and the necessity of transdisciplinary approaches does not imply the disappearance of traditional disciplines. (Jandrić \& Hayes, 2019)

Therefore, if the identity of a human is constructed differently across different disciplinary fields, and as Mark Poster (1990) observed, the discipline of computer science is identified through its relationship to the computer, the distinction can remain (Hall, 2013). These HCI disruptions though are bringing the cultural concerns of the humanities to bear on computing in novel ways that 
can bring the disciplines into powerful dialogue. A dialogue that now needs to be acknowledged in university policymaking for inclusivity, because equality, diversity and all manner of inequalities are intimately constructed, and reconstructed, via digital interactions with computers that can keep people on the margins:

In the postdigital age, the concept of the margins has not disappeared, but it has become somewhat marginal in its own right. We need to develop a new language of describing what we mean by 'marginal voices' in the social relations between knowledge production and academic publication. Universities require new strategies for cohabitation of, and collaboration between, various socio-technological actors, and new postdigital politics and practice of knowledge production and academic publishing. (Jandrić \& Hayes, 2019)

\subsection{Writing More Inclusive Postdigital Policy That Considers Positionality and 'Dataism'}

It is now vital (given the vast amount of academic publication during the pandemic) to raise awareness of the intimate flow of knowledge that is passing between the humanities and computing, and to critically and honestly represent this in university policy. If universities continue to treat technology on the one hand, as merely a rational way to fix processes or enhance teaching in some HE strategies, but omit the consequences of digital technologies on the other hand from strategies for equality, diversity and inclusion, the implications are stark. The university agendas or frameworks aimed at inclusion, will be biased themselves. This means they will remain flawed approaches towards addressing all manner of inequities and simply linger (on the shelf or the hard drive) as disconnected McPolicy (Hayes, 2019a).

In postdigital society, positionality matters. Whilst it is increasingly difficult to separate who (or what) is contributing to the 'viral' viewpoints that spread rapidly across the Internet, at the same time as the Covid-19 virus claims lives, each human being has a positionality. In our postdigital contexts, individual positionality no longer sits apart from a 'fusion of living and technological systems' (Peters, Jandrić \& McLaren, 202O: 3) from biodiversity, or from sustainability (Jandrić et al., 2020). Each of our self-declared positionings are protected by the Equality Act (2010), the Public Sector Equality Duty (2011) and the Equality and Human Rights Commission (2019), amongst other legislation. In order for university policy to reflect and uphold social justice, the hidden design and programming processes that reinforce existing inequalities, alongside exclusionary policy language, need to be addressed. This is not least because: 
Metadata and data have become a regular currency for citizens to pay for their communication services and security - a trade-off that has nestled into the comfort zone of most people. (Van Dijck, 2014)

What we often fail to notice, and has yet to be represented in HE policy, is the problem that:

Datafication is rooted in problematic ontological and epistemological claims. As part of a larger social media logic, it shows characteristics of a widespread secular belief. Dataism, as this conviction is called, is so successful because masses of people - naively or unwittingly - trust their personal information to corporate platforms. The notion of trust becomes more problematic because people's faith is extended to other public institutions (e.g. academic research and law enforcement) that handle their (meta)data. (Van Dijck, 2014)

Van Dijck points to an 'interlocking of government, business, and academia in the adaptation of this ideology' and recommends an approach that looks more critically at 'the entire ecosystem of connective media (Van Dijck, 2014). This is an ecosystem of connective media that includes HE policy. Policy therefore cannot meaningfully sit apart from social media, the corporate platforms universities have adopted, flawed approaches towards collecting (meta)data for research publications, or data for excellence frameworks, such as the Teaching Excellence and Student Outcomes Framework (TEF) (Office for Students, 2019), the Knowledge Exchange Framework (KEF) (2O2O) or the Research Excellence Framework (REF) (2021). Such claims of excellence in the policy discourse do not sit apart either, from the potentially flawed methodologies or platforms on which these are based.

\subsection{Data-Driven Policy Frameworks of 'Excellence' Bring Risks to Inclusive Practices}

There are irrational aspects to utilising 'various computational methods (usually associated with artificial intelligences, deep learning, and such) to help us manage large amounts of information' (Jandrić, 2019) when this information is actually critical theory or inclusivity policy. However, as it is necessary to adopt such techniques, reflexivity about what this means can help to acknowledge that potential bias and ethical issues prevail until these can be addressed. In critical research projects using certain software or technological interventions it is an important requirement for a researcher to do just this. To reflexively acknowledge, as part of their positionality statement, how the use of such systems might 
affect their outcomes or influence what is reported from the data. It is necessary then to disrupt both design assumptions behind platforms and metadata, as the above examples demonstrate, but also to challenge critical theories and university inclusivity policies, if they fail to acknowledge that commercial software used in data collection and analysis can have bias and manipulation infused through it. This becomes particularly important if policy frameworks that regulate what universities do, via data, make bold claims of 'excellence'.

In UK universities, such claims are applied to both processes and people, which again broadly implicate both computing and the humanities, in terms of the critical analysis of what this means in practice. The award of National Teaching Fellowships and University Teaching Fellowships (Advance HE) is based on an assumed relationship between teaching fellows and excellent teaching. However, research conducted with recipients found that fellows did not change their practice after receiving their Fellowship, as they simply accepted that they were already 'excellent'. The most significant impact was 'affirmation': an acknowledgement that their work was excellent, giving them 'permission' to continue (Warnes, 2020). Irrationality is revealed then through the rational McPolicy of awarding 'excellence', if this manifests in an acceptance that we have 'done enough', rather than an ongoing striving to do better. I can attest to this somewhat myself, as a Principal Fellow of the HEA (PFHEA), since 2016. However, if such awards are establishing a level of attainment alone, this is not unlike accepting that 'the principles of inclusive practice are well established' (Department for Education, 2017). If these become static principles, they then defeat the object of inclusivity, which is ongoing and dynamic, as new challenges constantly arise.

Yet challenging what sounds like a common sense goal of 'excellence' is not an easy thing to do, as Bartram (2020) points out:

Taken at face value, it may initially seem difficult to argue with the sentiments enshrined in the rhetoric that surrounds the TEF - raising the status of teaching in Higher Education, re-balancing its relationship with research, incentivising institutions to focus on the quality of teaching, and making them more accountable for how well they ensure excellent outcomes for their students in terms of graduate-level employment or further study'. (OfS, 2018:1, Bartram, 2020)

Whilst these can sound like 'laudable aspirations', Bartram (2020) demonstrates through queer theory that the TEF is emerging not only 'as a landmark initiative that is designed to further embed a neoliberal audit and monitoring culture into Higher Education' (Rudd, 2017:59) but as: 
a constraining exercise that restrains diversity and limits potential. (Bartram, 2020)

This is because 'TEF operates to normalise a macho consumerist identity' (Bartram, 2020). Such an imposed identity is argued to be consistent with a neoliberal philosophy of 'closing off alternative approaches' (Saunders, 2015: 403). It does this by locating $\mathrm{HE}$ firmly within a masculinist business ontology, whereby institutions, lecturers and students are systematically conditioned into compliance with a consumerist vision of universities that redefines how we come to see their purpose, the ways in which we judge their worth, and indeed how we behave and engage (Bartram, 2020). Bartram cites Rudd (2017: 73) in explaining that such a vision has become embedded as compliance in a wider discourse of newly constructed 'realities', both through conscious resignation, and more efficiently, through unconscious compliance. A queer analysis would concur that the TEF has helped to perpetuate and privilege this vision. Therefore, 'cross-examining its essentialising assumptions and reductive effects in order to de-normativise its hegemonic control is part of queer theory's raison d'être (Bartram, 2020).

Finding points of connection via queer theory between these observations on TEF bias from Bartram and those of DeVito et al. (2020) on queer theory in HCI to support Lesbian, Gay, Bisexual, Transgender, Queer, Intersex, Asexual (LGBTQIA), are powerful in demonstrating a dual resistance from both humanities and computing, to totalising McPolicy agendas. For DeVito et al. (2020), a redefinition of Queer HCI is:

Research in HCI by, for, or substantially shaped by the queer community itself and/or queering methods and theory, regardless of application subdomain. (DeVito et al., 2020)

These researchers argue that as Queer Human-Computer Interaction (HCI) becomes an established part of the larger field, both as research on, and with, queer populations and in terms of employing queering theories and methods, the role of queer researchers and their positionalities will benefit from support. Queer people are now doing HCI research not specific to queer populations, but it is necessary to ensure that their allied researcher partners beyond the queer community develop the appropriate sensitivity and background knowledge to approach queer topics productively and respectfully (DeVito et al., 2020: 2).

It is therefore important that such research informs inclusivity policy for universities. If metrics, statistics and datasets are being brought together to 
endorse judgements of excellence (Shattock, 2018: 21) and applied in the context of inclusivity, then the diverse experiences from the queer community can hold such rational objective assumptions to account. This becomes a stronger account still when it is voiced across both the humanities and computing. Postdigital positionality enables such a dialogue to include in this, all other cross-disciplinary and individual perspectives. This shifts the focus in policy discourse on inclusivity to be less about what 'the university' is doing. It helps it move closer towards what the people of the university, together with those in civic society, are doing, as postdigital individuals, but working collectively to support all of us to feel included.

\section{$2 \quad$ Airing Debate on Postdigital Positionality}

Everyone in the virtual airing cupboard seems to have an opinion of some sort. Then there are the voices that are not aired over the Internet belonging to people that universities still seek to reach. The second half of Chapter 2 examines why recognition of shared political economic spaces of technology and culture are important for airing varied debates on what inclusivity means. Such debate needs to take the ethos of a university outwards (Hayes et al., 2020), not try to bring 'inclusion and diversity' inside walls that no longer exist. Traxler has argued for:

The need for a higher education sector engaged and 'included' in its society. (Traxler, 2020)

The policy that universities write concerning inclusion needs to reflect a new understanding of the unique fusion of culture and technology with individual identity in each of us. As such looking outwards as well as inwards is necessary. Universities are not a separate set of walls, as empty campuses during the pandemic have attested. The people from those campuses have been working and studying out in the virtual airing cupboard. We have all been off learning what it is like to be on the outside looking back into the campus, under the most abnormal circumstances. Yet this is a situation that could actually be part of what we each come to see as our own 'new normal'. The individual perspectives that staff and students bring back to share on this experience are vital to the debate on postdigital positionality and indeed to the post-pandemic university (Carrigan, 2020a).

When I made the analogy with the airing cupboard at the start of this book, I reflected on Covid-19 and its close connection with the human need for 
ventilation. The life-threatening virus has revealed in particular the fragility of life for anyone with underlying respiratory conditions. Early in the global crisis, the availability of the technology to breathe for them (ventilators) was dependent on the economies of supply and demand, levels of manufacturing capacity, politics concerning deliveries between countries and the skills and training of enough staff to operate this equipment (Kliff, Satariano, Silver-Greenberg \& Kulish, 2020). There were physical ramifications for the positionality of people from different cultures with these health concerns and therefore close links with inclusivity and diversity agendas.

It was soon noted that different ethnic groups were displaying a greater chance of having complications from the virus, requiring access to ventilation, but not necessarily receiving it, with views on this situation aired widely across the Internet. During lockdown, protests across the globe have arisen in relation to racism, disadvantage and the wide disparities that occur between different groups. Calls for 'getting woke' in terms of being 'acutely aware of racial and social injustice' are concerned with an ongoing awareness and learning from a position of understanding systemic and institutional forms of racism. The dimensions of argument expressed on this topic can range from encouraging activism that might critically disrupt the system of racial oppression in education (Roy, 2018), analysing 'whiteness' in digital text (Matias, 2020), or arguing that activist scholarship has now 'made everything about race, gender and identity' (Pluckrose \& Lindsay, 2020). There has been a move by politicians, officials and the media to adopt the now widely used term Black Asian Minority Ethnic (BAME) in discussion of ethnic minority groups. Questions have been asked though about whether anyone in real life 'would refer to themselves as BAME' (Sandhu, 2018). The current UK Home Secretary, Priti Patel, has been reported to have called the BAME label 'patronising', 'insulting' and 'totally unhelpful' and it has also become an 'arguably overused term' that 'leaves little room for individuality or distinction' (Barrett, 2018, Osamor, 2020). BAME emerged from the use of Black Minority Ethnic (BME) a term with roots in the idea of 'political blackness', which refers to various ethnic groups gathering to fight against discrimination. It was a term used by many in the anti-racist movement in the UK in the 1970s (Sandhu, 2018).

In the 199os though 'it was argued that the umbrella term lumped different minorities together, which was not only confusing, but it also gave less prominence to the identity of British Asians. The 'A' for Asian in BAME was then included' (Dawson \& Thompson, 2019). Two main arguments that crop up are, firstly, that the term BAME 'has negative connotations or that it is too heavyhanded to be used to describe extremely diverse groups of people'. Secondly, 
by way of contrast, is that it is a useful term, that there needs to be an effective way of referring to people's heritage in official reports, and a term like BAME is useful when speaking out against racial inequality (Dawson \& Thompson, 2019). Objectivity and subjectivity seem once again to be in debate here, with the rationality of the language of official reports potentially stated as a reason to retain a more generic term for a hugely diverse group. Whilst others argue for subjectivity stating that 'identity is a personal thing and shouldn't be described as a generic term' (Dawson \& Thompson, 2019).

Wherever readers of this book sit, in terms of the positions that they take on these and many other topics of social justice, I argue that it is necessary to also 'include' in our policies the 'work' of intelligent digital technologies and datadriven systems across the World Wide Web. These are the platforms on which we are now 'airing' our views about equality, diversity and inclusivity. They are deeply implicated in how we form our views on current cultural dilemmas in society. As such, these are not neutral systems and devices. They co-shape the data we use and the identities we have both on and offline. They are seamlessly operating as layers between teachers, students, researchers and policymakers. For these reasons alone, getting to know who developed the systems we use, what their decisions are based on and the forms of changes to educational values they are now influencing are just some of the reasons to engage with developers. Anticipating who might become our future systems designers and programmers is also important so that they might be a part of debates on how data is classified and the role of their own positionalities in such decisions.

\subsection{Systems Linked to the Virtual Airing Cupboard and Their Living Developers}

It is not as difficult as it sounds to include data-driven digital technologies at the policy table. This is because they are so recently developed, are still developing, and their developers are still around to contact and invite into the postdigital positionality debate:

internet has only just entered its sixth decade: there are 1.7 billion people alive on the planet who were born before its invention. It's only been a mass phenomenon for 20 years. Many of its biggest companies are still run by the people who founded them; much of its architecture was built by people who are still alive and looking into the effects of what they began. (Ball, 2020: 219)

James Ball (2020) also points out that: 
The internet is the product of a long chain of human decisions and incentives. It is not some force imposed upon us. But what's striking is how much it feels like that. (Ball, 2020: 219)

Then despite the multitude of voices, arguments across social media and the cancel culture wars, as humans, we have this rather odd but valuable point of connection too. What links people using the virtual airing cupboard of the Internet is that 'almost none of them feel like they're in control' (Ball, 2020: 219).

It may sound pessimistic, but this is also a starting point for change. If even 'the people who built the internet's infrastructure say the huge global network today doesn't feel like the result of what they built' (Ball, 2020: 219) then we have some consensus to debate where we might go next. It is though, a pressing debate given the 'data-driven online ad model' that has made it so easy for the Internet giants to own and transfer people's data and to apply algorithms despite their systemic inequality or bias (Ball, 2020: 232). Ball points out that the physical infrastructure of the Internet is not fundamentally all that different from its early origins. The Internet we engage with now is still a network of cables and lines that grew from technology used by its predecessors (Ball, 2020: 220). However, the intelligent technologies and related data that now network through the Internet are different. New generation architecture has emerged, and new companies and nations are stepping in to manage these. Ball suggests this is a spur to action to avoid the norms and priorities that authoritarian regimes could bring to managing related security and privacy protections (Ball, 2020: 233).

As an example, the earlier concerns about facial recognition software and bias can be met with forms of resistance beyond those involving lawsuits against authorities. Scheuerman, Wade, Lustig and Brubaker (2020) looked into 'how identity is operationalized in new technical systems'. They focused on how race and gender are defined and annotated in image databases used for facial analysis. Their findings revealed that:

The majority of image databases rarely contain underlying source material for how those identities are defined. Further, when they are annotated with race and gender information, database authors rarely describe the process of annotation. Instead, classifications of race and gender are portrayed as insignificant, indisputable, and apolitical. (Scheuerman, Wade, Lustig \& Brubaker, 2020: 1)

Describing how literally within the last decade, facial analysis technology has 'transitioned from a theoretical research problem to commercial reality', 
these researchers point to the many technologies in which facial recognition is already embedded. It is used in social media, for unlocking access to devices, by law enforcement and even to track consumer behaviour inside stores for future marketing campaigns targeting specific demographics. The use of human identity characteristics in machine learning databases have caused concern for some time over race and gender bias. However, attempts to mitigate this and to build more diverse databases with the aim of creating fairer outcomes remain simplistic and lacking in critical and social theories (Scheuerman, Wade, Lustig \& Brubaker, 2020: 2).

Additional concerns are that 'machine learning and human-computer interaction (HCI) communities do not have an agreed upon approach to how diversity is being operationalized in training and evaluation databases'. Scheuerman, Wade, Lustig and Brubaker (2020) refer to unethical attempts to address this, such as Google reportedly targeting homeless people to use their images to improve their face unlock system (Hollister, 2019). The need to more meaningfully represent race and gender in databases is important to address the current opaque and inconsistent approaches. However, Scheuerman, Wade, Lustig and Brubaker (2020) took this further in seeking to understand underlying decisions that become embedded into the construction of training and evaluation databases. They examined these, alongside critical scholarship dealing with the complex realities of identity. Following their analysis of 92 image databases to look at why race and gender are included, what information is implicit or explicit and what sources and annotation practices are used to define categories of race and gender, they recommended that facial analysis researchers adopt a sociohistorical perspective when making decisions around classifications of race and gender and that they embrace their own positionality in terms of embedding such classifications (Scheuerman, Wade, Lustig \& Brubaker, 2020: 2).

Studies of this nature are valuable to cite against the problems of digital skills agendas that are taught, or learned, in a vacuum or treated as detached attributes. Instead, whatever levels of digital skills are being developed in trainees, there is a need for training and educational agencies who offer such programmes to understand the wider ecosystem that surrounds digital skills acquisition.

\subsection{Positionality Is a Key Consideration for All Digital Skills Agendas}

Positionality needs to be addressed both for those teaching and those who are learning, so that bias and ethics are discussed in digital skills and computer coding programmes and critical research on diversity is included. Moving beyond the decisions made by those programming systems, to the background and identity of developers and programmers themselves, there are considerations of representation from minority groups moving into these professions. 
Codding Mouza, Rolón-Dow and Pollock (2019) describe an initiative which was intended to broaden the participation of minoritised youth in computer science and to offer culturally responsive computer science programming in informal settings. They undertook this work within a theoretical framework of positionality, in order to take into account the 'numerous shifting and intersecting identities of each individual' involved. They argue that 'educators are positioned by factors such as age, gender, race, and lived experiences'. As such, they declared a need to scrutinise the positionality of their own facilitators, to look at how their community affiliations, organisational roles, and personal identities might influence the process and findings of their community-based research and computer science programming.

In seeking to create programmes that would serve underrepresented minoritised and female youth they adopted strategies that included methods for engaging youth, and practices that build on the knowledge and assets of local communities, using undergraduate computer science students as facilitators and near-peer mentors, and encouraging culturally responsive interactions between facilitators and the young participants who were underrepresented in computer science (Codding, Mouza, Rolón-Dow \& Pollock, 2019). Based on such approaches there is evidence for building many more coding programmes and digital skills training initiatives from within local communities, but with cross-sector representation and broad diversity amongst the facilitators. This approach addresses a shortage in skilled computer programmers from the point of their positionalities first. Furthermore, in recruiting from diverse local communities where there are already initiatives in place to support life chances for local minority and disadvantaged groups there is an ecological infrastructure already in place to support inclusive practices.

The role of positionality in the examples above is further endorsed by Kaeser-Chen, Dubois, Schüür and Moss (2020) who argue that:

Being positionality-aware is key for machine learning practitioners to acknowledge and embrace the necessary choices embedded in machine learning by its creators. (Kaeser-Chen, Dubois, Schüür \& Moss, 2020)

Shifting the focus now a little towards the networked devices on which so much of our postdigital positionalities are now enacted, there are new challenges and opportunities to reflect on as AI continues to develop and to be added to the Internet of Things (IoT). These include device updates, protocols and user awareness for example, now that IoT devices and applications are playing an increasing role in modern life. It may seem that the networking of household items to the Internet is not immediately the concern of a university inclusivity 
policy, but the use of smart systems on campus or in university accommodation are being introduced in all sorts of ways.

From smart campuses that optimise power consumption to ones that enable students to use their phones to check if washing machines are free, there are new examples continually appearing. Some campuses are acting as test-beds to inform digital decisions for surrounding communities, thus there are new public-private commercial partnerships involved. Most universities already have the campus-wide wifi needed with the ability to link the personal devices of staff and students. This means they may well be able to utilise IoT to connect all manner of wearable and connectable devices and data which can be argued to benefit students. Yet as companies lobby universities to sign up for the IoT, it is worth doing some additional reading between the lines, when new interpretations of inclusion and equity accompany the glossy brochure. In Deloitte's (2019) Smart Campus document there are some bold claims on the benefits to 'foster inclusion and equity':

Understanding the patterns around various activities and initiatives within a campus can help a school foster inclusion and drive equity. Dashboards designed around inclusion and diversity can provide valuable, actionable insight. The knowledge gained from education drives the economy and improving access to education will only foster a more inclusive community. (Deloitte, 2019)

The assumptions that 'equity' is something an institution can 'drive' is discussed in the context of dashboards that have been 'designed around inclusion and diversity' (Deloitte, 2019). Universities would need to explore such arguments concerning claims of inclusion in considerable depth, to avoid the problem of treating IoT as just another quick fix.

\subsection{Learning Lessons from My Airing Cupboard}

Perhaps though, given all of these developments, I might reflect on what could be in store for my airing cupboard in the hall and whether its architecture is heading for a revamp anytime soon. If I go out just now and I open the door of my airing cupboard to search behind the pile of towels and sheets I can just about see the machinery that sits at the back. I can spot some of the water tank and pipes (Figure 29) and a tatty label that at least clearly identifies what the specifications of the copper cylinder are (Figure 30). Searching my airing cupboard like this will not though cause me to be identified by those who live in a house further along my street, or in a different part of the world. No one holds data about what items I store in my hallway airing cupboard (which is just as well). 

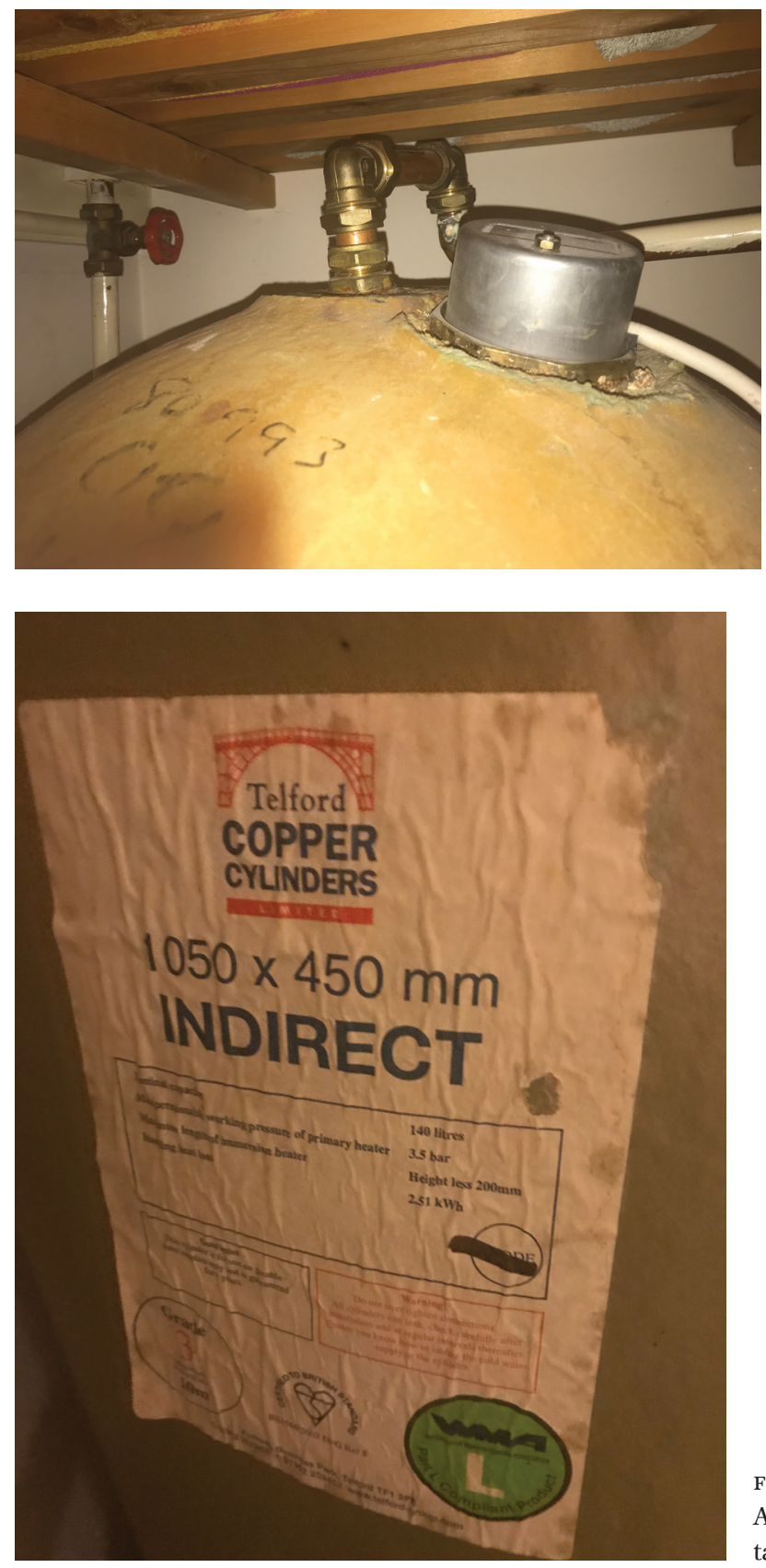

FIGURE 29

An airing cupboard hot water tank infrastructure
FIGURE 30

An airing cupboard water tank specifications

No one tracks what I search for in there, what I download as the sheets topple down on top of me or captures evidence that the cat has managed to sneak in there for a warm sleep. My airing cupboard does not have a relationship 
(that I am aware of at least) with any other airing cupboards in houses along my street. They do not share data with each other in the way that my phone, iPad and laptop do.

Sitting back in front of my laptop again then, I get little sense of what lies behind my Google searches for sources for this book, or where the 'likes' I have registered on Facebook might be stored, counted or passed on.

After my guilty glance at some click bait earlier to read someone else's dirty laundry story, I have no idea how often I will now be prompted to read related topics. Nor does the complexity of the architecture behind the Internet seem to be any particular issue to me right now. I have my active wifi and I can connect wherever I go. This is also a problem though, if I do not notice the ethical problems and security issues that have crept in alongside my constant searches for everything in the virtual airing cupboard. Unlike the laundry sitting dormant on the shelves in my cupboard in the hall, my laundry I air online is accessible to all. What if my airing cupboard in the hall now decides to join in too? Could I stop it from making connections with the virtual airing cupboard? Fortunately, yes, I do have that choice right now (I think).

I also have a choice though to actively connect my airing cupboard water tank to my wifi network via a new app that will give me visibility on every aspect of my hot water activity. To put it another way, I can join the 'Internet of Tanks' and learn what I wish about my hot water cylinder's story, as shown in Figure 31.

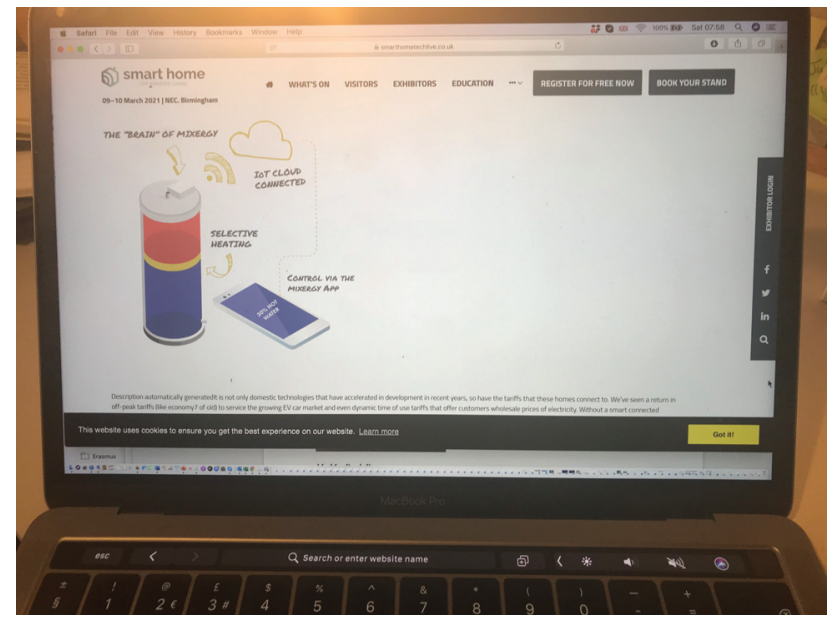

FIGURE 31

My laptop showing the Internet of Tanks opportunity

This includes the exact percentage of hot water available in the cylinder, how much energy has been used, the status of pasteurisation cycles, switching of energy sources and even, information about the energy mix and carbon 
intensity of the national grid's energy (Mixergy, 2020). In this sense, as I leave home to go for a drink in a nearby pub (before the next lockdown forbids it) I am taking my airing cupboard cylinder along with me, to be sociable too. Given that we can connect home devices in this way and carry any number of apps with us on our mobile phones, in a sense they have already made it into the small room on campus or online where people are busy discussing and writing the next university inclusivity policy. Digital solutions bring additional complications and unpredictability to a world that is already rapidly changing in response to a global pandemic. Data-driven systems are involved across all of our postdigital society. They have earned their place at the policy table (which may well be a virtual table currently). We need to accommodate their actions alongside our own, in ethical debates on social justice, human rights and capabilities in all HE policy discourse that seeks to effect change.

\subsection{Virtual Airing Cupboards Ventilate and Constitute Viewpoints}

Our large societal, postdigital 'airing cupboard' allows ventilation of many mutually constitutive viewpoints across both physical and online spaces. These are not set apart from universities as further examples will show. University policies cannot socially isolate either from the broader cultural/technical communication taking place on the communicable Covid-19 virus. Conditions in the virtual airing cupboard are not unlike the acts of droplets we fear coming into contact with from the virus, if we have too close an encounter with someone who might spread the disease. Our shared digital online communications systems have made it easy for any dialogue to pick up traces from other different institutional or personal positionalities, with implications for how inclusive practices in $\mathrm{HE}$, and related policy, are now constructed and perceived.

In recent examples, ranging from the activities of celebrities to academics, the complexities of actions and reactions on topics relating to race can be noticed. The stances individuals take also have relevance to the institutions in which they work. When the singer Adele was accused of cultural appropriation, others argued that this is cultural celebration, in the context of the Notting Hill Carnival. The arguments posted online after she was pictured on Instagram wearing bantu knots, a traditional African hairstyle and a bikini in the design of the Jamaican flag, ranged from intense criticism to compliments and support for the musician (PA Media, 2020). One person concluded that 'this officially marks all of the top white women in pop as problematic', another suggested 'she should go to jail no parole for this'. Different viewpoints (including Labour members of parliament and other celebrities) tweeted in 
her defence: 'Poppycock! This humbug totally misses the spirit of Notting Hill Carnival and the tradition of "dress up" or "masquerade" Adele was born and raised in Tottenham she gets it more than most. Thank you, Adele. Forget the Haters' (Lammy, 2020).

However, new dimensions of personal positionality (and potential cultural implications) were revealed when Jessica Krug, the 'prominent activist and professor of African American history at George Washington University', when writing on a blog called Medium, 'admitted that she has been pretending to be a black woman'. She 'revealed that she had assumed many false identities including "North African Blackness, US rooted Blackness (and) Caribbean rooted Bronx Blackness"' (Sibthorpe, 2020). Her blog claimed too that her own trauma and mental health in her teens may have contributed to her claiming identities that were not her own:

I have eschewed my lived experience as a white Jewish child in suburban Kansas City under various assumed identities within a Blackness that I had no right to claim... I am not a culture vulture. I am a culture leech. (Krug, 2020)

These revelations raise some different questions on cancel culture. What happens when a person cancels themselves to the extent that they feel they no longer have a positionality? Then there are the intersections between inclusivity and mental health that are also presented by this case.

The global 'war' against Covid-19 has a dual effect, as the communicable, biological aspects of the contagion are fought by science and technology. At the same time technology, culture and language are 'transmitting' the informational aspects of the biological threat (Peters, Jandrić \& McLaren, 2020). Examining how dimensions of 'cancel culture' flow through HE via digital technologies and human beings (together) demonstrates why such dynamic forces cannot simply be 'owned' by a set of inclusion guidelines. This is partly for cultural reasons, because any guidelines and related data have been shaped by the values, deadlines and critical levels of understanding or bias of the individual or committee who have written them, or adapted them from another university policy document (Hayes, 2019a). Then there are issues of inherent bias already discussed which may be programmed into technologies themselves that can also be responsible for 'cancelling' humans in all sorts of ways. Such bias is continually in interaction with data of many kinds which is also potentially biased. Datasets reflect the values and ideologies of their collectors, whether the topics concern ability, disability, ethnicity or gender, or indeed 
other terms we have come to use. As such they perform such concepts 'into being' (O'Keeffe, 2017: 133).

\subsection{The Contagion of Cancel Culture and the Educationalisation of Inclusivity}

Elsewhere I have written with co-authors about the problems arising from educationalisation of many different societal issues into agendas for schools and universities to be responsible for (Peters, Jandrić \& Hayes, 2018, Jandrić \& Hayes, 2020d). Larry Cuban, in discussion with Petar Jandrić (2020) described the process of 'educationalising' as:

Transferring societal structural problems to the institution of schooling so individual students and teachers then become first, an easy target to blame, and second, responsible for solving the problem. For example, national health problems of smoking tobacco and drinking alcohol in the prior century got translated into school courses for youth about the physical and cognitive damages done by both drugs. Too many road accidents? Driver training and completing a safe driver's course for high school graduation became a school-based solution to a national problem. And as you pointed out in your question, the harnessing of schools to an increasingly high-tech economy means that children and youth are engaged early and persistently in using electronic devices so that they can easily fit into a high-tech workplace. (Cuban, in Jandrić, 2017:13)

It is therefore not that unexpected to see the notion of 'cancel culture' being shipped into schools for teachers to tackle. Reserving any personal judgement on the pros and cons of linking cancel culture with teaching about bullying in schools, the initiative is being aimed at secondary schools:

As part of the Government's drive to protect freedom of speech, secondary school students will learn that people with controversial opinions should be respected. (White, 2020)

MP Andrea Jenkyns tweeted (with an integral pun on the Commons):

Great, commons sense prevails! Woke 'cancel culture' is a form of bullying, pupils will be taught, as part of the Governments drive to protect free speech. (Jenkyns, 202ob) 
Taking steps to address cancel culture has importance though across all parts of society. It requires ongoing critical debate that universities could potentially lead on, but are not in a position to control any more than schools are:

In Department for Education training manuals, teachers are instructed to tell pupils that the 'cancel culture' which has taken root at many universities - where individuals call for a boycott of a person or company whose views they don't agree with, in the hope they lose their job or clients - is not part of a 'tolerant and free society'. (White, 2020)

Stating: 'the 'cancel culture' which has taken root at many universities' as a justification for educationalising a deeply ingrained socio-technical practice raises a number of issues. Firstly, it gives an impression that university is simply a continuation of school. The bias here is against lifelong learners, those made redundant through the pandemic seeking to retrain, apprentices and indeed university staff. Secondly, there is a more fundamental problem of persistently separating the teaching of cultural values from critical digital skills that would raise awareness of how these intertwine and constitute each other. Thirdly, a rather more 'sinister' link can be made. One that reveals another irrationality in how one set of rational agendas to promote inclusivity can effectively 'cancel' another.

Whilst only flagged as guidance or principles, schools have been asked not to use resources from organisations that take extreme political stances, including those who express a desire to 'end capitalism' (gov.uk, 2020b). In guidance on how schools might set up the relationship between sex and health in the curriculum, the DfE categorised anti-capitalism as an 'extreme political stance', equating it with opposition to freedom of speech, anti-Semitism and endorsement of illegal activity (Speare-Cole, 2020). A further issue concerns why, if we do seek to educationalise ways to address cancel culture, would we only begin programmes at the secondary school level, when infants now operate iPads, phones and laptops as soon as they are able to hold these. The State of Data (2020) report recently suggested too that:

Children have lost control of their digital footprint by their fifth birthday from being in state education. (The State of Data, 2020)

This raises two interconnected issues in relation to the dialectics between technology and culture. If, as part of a tolerant and free society, children are to be taught not to 'cancel each other' as part of their cultural education, why does it 
seem that, from the earliest age possible, technological systems are effectively 'cancelling' the positionalities of children, through the school system, as they become 'datafied' as individuals? (Lupton \& Williamson, 2017).

\subsection{Stalked by Data in an Ongoing Identity Theft?}

The State of Data report (2020) charts an alarming 'datafication of children' in the UK and points to how England's education system has also managed the "exclusion and "managed moves" of outliers - the disabled, the lower achieving and those who won't get good grades' (The State of Data, 2020: 74). Particularly alarming is the forcing of schools:

to turn the complexity of children's lives into simplified progress scores or attendance ratings without context, to be ranked and spanked in league tables by the national Regulator. (The State of Data, 2020: 75)

The authors argue that a form of identity theft is taking place from an early age through which children are no longer afforded space to make mistakes. This would seem to be upheld too by concerns over a use of AI to read young children's emotions whilst they learn. Yet a software called 4 Little Trees that measures muscle points on children's faces via a camera on their computer or tablet, and identifies emotions such as happiness, sadness, anger, surprise and fear, is argued to 'make the virtual classroom as good as - or better than - the real thing' (Chan, 2021). Claims that the software facilitates better interaction need to be balanced though with other elements of positionality, such as privacy and potential bias. Given that research has shown that some emotional analysis technology has difficulties 'in identifying the emotions of darker skinned faces, in part because the algorithm is shaped by human bias and learns how to identify emotions from mostly white faces' (Chan, 2021) the goal 'to train machines to be better than the average human' at reading facial expressions in relation to learning still sparks controversy (Chan, 2021).

Whilst the conditions of the pandemic lockdowns may seem like a separate set of challenges for schools, children and their families, through a postdigital perspective these are likely to compound each other in relation to both technology and culture. The physical restrictions placed on children, such as new sets of rules and regulations to observe, even in local play areas (Figures $3^{2}$ and 33), do not sit apart from those they are required to follow in school or online. It is worth reflecting more broadly therefore on the different forms of identity theft that might impact young people, through physical Covid-19 restrictions and virtual encounters. 


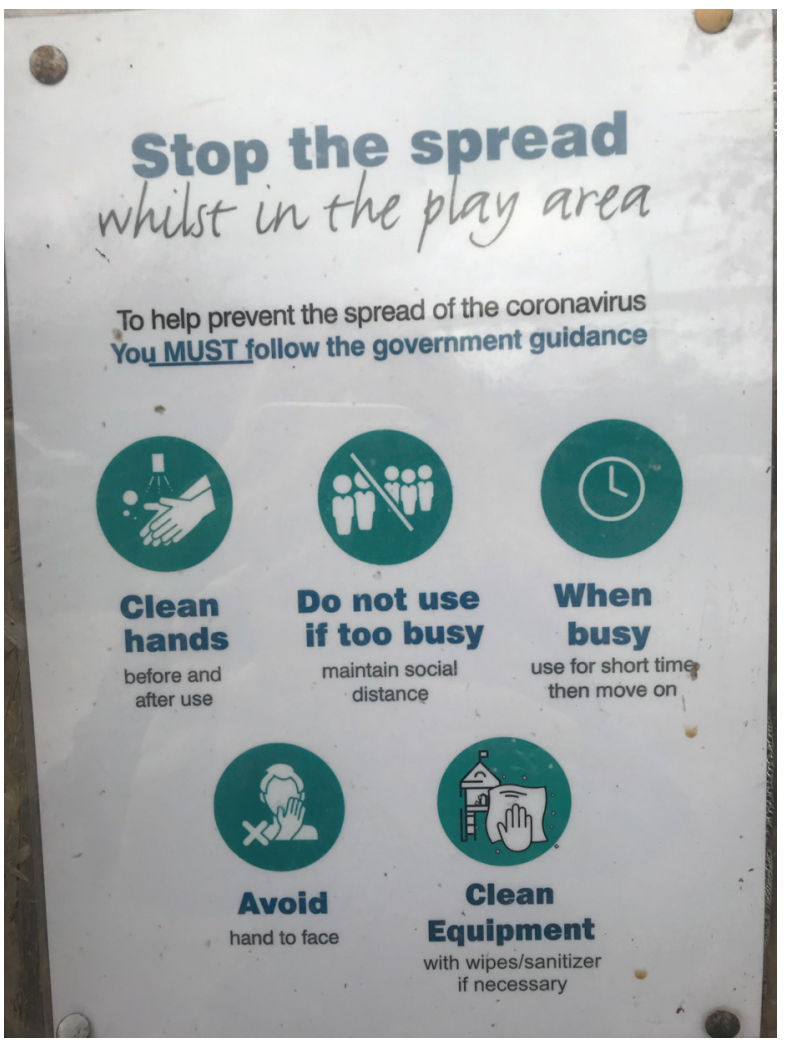

FIGURE 32

Covid-19 government guidance to 'stop the spread' whilst in a children's play area

\section{The rules:}

Please behave responsibly and remember the importance of social distancing

Please bring your own hand sanitiser and ensure your child sanitises their hands before entering play area and again when they leave

- Please use your own wipes to clean the equipment before use if you consider it necessary

- No eating or drinking whilst using the play area and equipment

- If, in your judgement, too many children are playing on the equipment. If, in your judgement, too mes away from the play area until others leave please wait at least 2 metres awa is safe to do so

and when busy, please use any particular piece of

- Be considerate, and when busy, please use any parchetdren use it equipment for only a short time and move on to lony parch you are accepting

- By allowing your child to enter this play area you

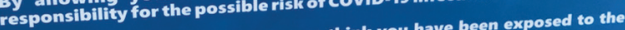

- If you have CoviD-19 symptoms or think you have

- If you you must stay at home and not use this phy following these rules Please help us keep this play area safe by following and exercising your own judgement

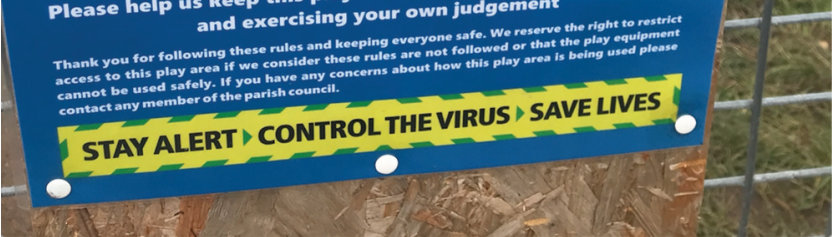

FIGURE 33

Covid-19 list of rules displayed in a children's play area 
Indeed, just because data systems make an activity possible does not mean that it is beneficial and in fact 'historic data can cause harm' (The State of Data, 2020: 75). To address this situation there are calls for a greater prioritising of access, inclusion, safety, privacy and a platform for young people's views on their digital rights (Coleman, Pothong, Vallejos \& Koene, 2017).

The process of airing the dirty laundry was once by word of mouth. Perhaps nods and whispers would have indicated that some people knew something about us we would have preferred them not to know. These days we really do not know what any person or agency could have access to, or whether it will work for or against us, as individuals. The data streams feeding the decisions that other humans or algorithms make about us are not at our disposal to learn why an application for a job, finance, a public service or a place at university is rejected. Such a situation impacts on the positionality of each of us in different ways in a postdigital society. Out there in the virtual airing cupboard are trails of my dirty laundry, but unlike the cupboard in my hallway I don't have a hope of clearing it out.

\subsection{Implications for HE Policy}

The university is no longer a discrete separate project detached from any of the examples raised so far. The virtual airing cupboard has seen to that. This leaves universities with the post-pandemic option of attempting to return to a 'normal' where a generation of discrete policies, one-by-one ticks a box for each issue as it arises, so that it can be educationalised into the curriculum or absorbed into staff training. However, issues of mental health and welfare do not reside in universities any more than disability or racism. Even if they did it seems unhelpful for the mental health concerns in relation to students and staff in HE to occupy a different set of policies to those concerning Technology Enhanced Learning (TEL), when the lockdown has clearly revealed just how interconnected these experiences can be.

An alternative to the singular, 'topic-based' manner in which HE strategies are frequently constructed could take a more person-focused, rather than topic-focused understanding. This approach could help to reveal the need to surface positionality instead of generality.

\subsection{Airing Cupboards and HE Policies Re-imagined as Living Literacies}

If humans are now data (Cheney-Lippold, 2018) then the question on my mind is: how much of this data is our own human narrative that is being rendered into something different? What routes might be open to us to preserve our own literacies? Recalling that a key 'challenge facing the university today is to 
link cultural reproduction and technological reproduction' (Delanty, 2001: 157) then perhaps there is a need to accept that our postdigital positionalities are made up of both. We are cultural and we are technological then, but we are also living conscious beings who bring our own literacies that are shaped by our identities and positioning. We breathe (when the virus lets us) and it is this living quality that could be helpful to remember in the process of collectively re-imagining our post-pandemic policymaking in universities.

In 'Living Literacies: Literacy for Social Change', Pahl, Rowsell, Collier, Pool, Rasool and Trzecak (2020) describe a living literacies approach as inclusive of official, schooled activities, such as reading, writing, speaking, and listening but also of tacit activities like scrolling through Instagram, watching the news footage and listening to music. This is a re-framing that goes beyond literacy as an object of study, to reimagine literacy as constantly in motion, vital, and dynamic and filled with personal affective intensities. They suggest that such a 'lived literacies' approach implies a turn to activism and to hopeful practice and creativity (Pahl, Rowsell, Collier, Pool, Rasool \& Trzecak, 2020).

Important to my earlier critique of McPolicy, is the way that these authors examine literacies through a series of active verbs, like seeing, disrupting, hoping, knowing, creating, and making. Where in McPolicy these verbs were so often ascribed to strategies and technologies, taking instead the notion of living literacies into policy would be to position policy itself differently. Rather than topic, or institution focused, policymaking would be positionality focused. Rather than talk of 'equality', 'diversity' or 'inclusivity' as detached 'objects' of study, these would be explored in the contexts of the individual 'subjects' they relate to. Such an approach has more chance of supporting inclusivity because it also raises awareness that all interactions surrounding inclusive practices are dynamic, not static. They are both human and nonhuman, digital and nondigital. They can exert agency in unseen ways, as can policy.

In The Good, the Bot, and the Ugly: Problematic Information and Critical Media Literacy in the Postdigital Era, Jiang and Vetter (2020) argue for a pedagogy of postdigital critical media literacy. Their postdigital examination of bots points out the ideological nature of the Wikipedia community and:

recognises bots as 'agents' that co-produce meanings with other social actors and human editors. Even though bots have contributed to the epistemic process of information validation on Wikipedia, the process has inevitably been made messy by the infiltration of misogyny, systemic bias, and conflict of interest on the online platform. A postdigital critical media literacy would encourage students to become more reflexive 
of online information validation through identifying and analyzing bothuman interaction. (Jiang \& Vetter, 2020)

In a similar fashion it is timely now to look at the manner in which HE inclusivity policy is formed and to become more reflexive about the possibility that, in its current shape, it simply confirms, rather than disrupts, existing systemic bias and entrenched inequalities. 